LBNL-51812

\title{
Solutions of Test Problems for Disposal of CO2 in SALINe Aquifers
}

\author{
Karsten Pruess and Julio García \\ Earth Sciences Division, Lawrence Berkeley National Laboratory \\ Berkeley, CA 94720, U.S.A.
}

December 2002

This work was supported by the U.S. Department of Energy through the Office of Basic Energy Sciences (BES) and through the National Energy Technology Laboratory (NETL) under Contract No. DE-AC03-76SF00098. 


\begin{abstract}
This report presents detailed results for three flow problems involving $\mathrm{CO} 2$ migration in saline aquifers, that had been posed as part of an international code intercomparison study. Selected data for PVT properties of aqueous mixtures involving $\mathrm{CO} 2$ are given, and the dynamics of immiscible displacement of an aqueous phase by supercritical CO2 is discussed. Simulations were conducted with a version of the TOUGH2 general purpose reservoir simulator that includes a special property package for supercritical $\mathrm{CO} 2$. The results can serve as benchmarks for debugging numerical simulation models.
\end{abstract}




\section{TABLE OF CONTENTS}

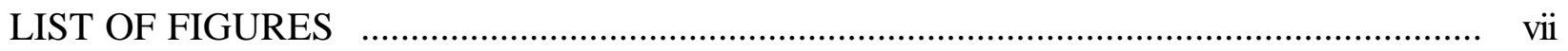

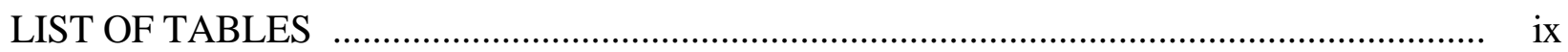

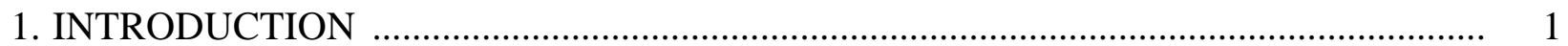

2. PROBLEM 3. RADIAL FLOW FROM A CO2 INJECTION WELL ............................... 2

2.1 Thermophysical Properties .............................................................................. 2

2.2 CO2 Injection into an Aquifer without Salinity ..................................................... 4

$2.3 \mathrm{CO} 2$ Injection into a Saline Aquifer .................................................................... 8

3. PROBLEM 4. CO2 DISCHARGE ALONG A FAULT ZONE ....................................... 12

3.1 Thermophysical Properties ........................................................................... 13

3.2 Gravity Equilibration ............................................................................... 13

3.3 CO2 Displacement ............................................................................ 15

3.4 Numerical Artifacts .................................................................................. 17

3.5 Non-isothermal Variation ....................................................................... 19

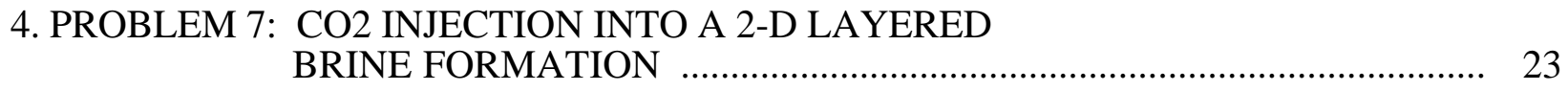

4.1 Thermophysical Properties ........................................................................... 24

4.2 Gravity Equilibration .................................................................................. 25

$4.3 \mathrm{CO} 2$ Injection ........................................................................................ 26

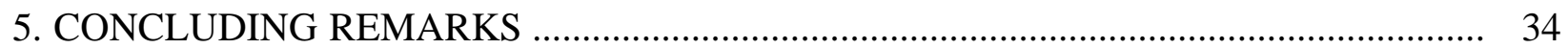

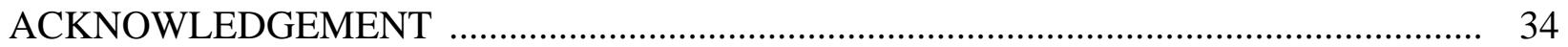

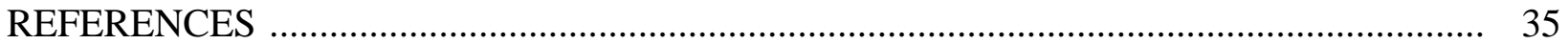

Appendix A. Test Problem 3 ………………………........................................................ 37

Appendix B. Test Problem 4 ............................................................................................ 39

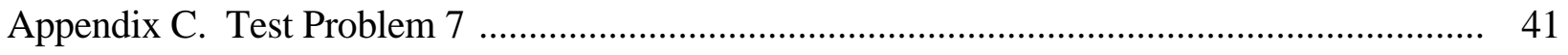




\section{LIST OF FIGURES}

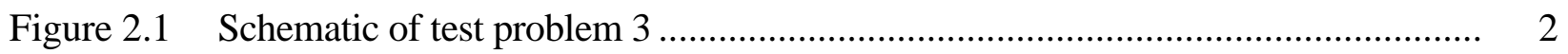

Figure 2.2 Simulated gas saturation front (no salinity) ............................................. 4

Figure 2.3 Simulated pressure (no salinity) ............................................................. 5

Figure 2.4 Simulated gas saturation (no salinity) .................................................. 5

Figure 2.5 Simulated dissolved $\mathrm{CO}_{2}$ mass fraction (no salinity) ................................... 6

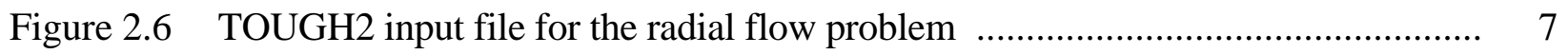

Figure 2.7 Simulated pressure (15 wt.- $\%$ salinity) ..................................................... 9

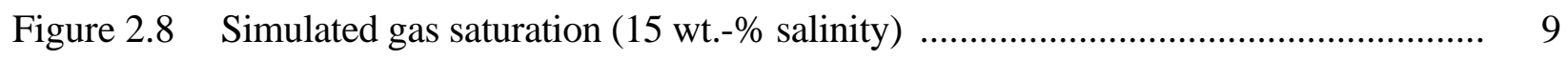

Figure 2.9 Simulated dissolved $\mathrm{CO}_{2}$ mass fraction (15 wt.-\% salinity) ........................... 10

Figure 2.10 Simulated solid salt saturation (15 wt.-\% salinity) …....................................... 10

Figure 2.11 Simulated solid salt saturation using a finer grid near the injection well $\ldots \ldots \ldots \ldots . . . . .11$

Figure 3.1 Schematic of the fault zone model (a) and applied boundary conditions (b).......... 12

Figure 3.2 TOUGH2 input file for fault zone problem ............................................ 14

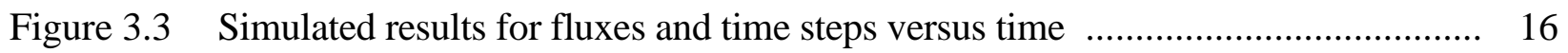

Figure 3.4 Gas saturation and dissolved $\mathrm{CO} 2$ mass fractions at times of $10^{7}$ and $2 \times 10^{7}$ seconds ................................................................ 17

Figure 3.5 Pressure profiles at times of $10^{7}$ and $2 \times 10^{7}$ seconds ................................. 18

Figure 3.6 Transient evolution of pressures and gas saturations at a monitoring grid block, $372.5 \mathrm{~m}$ up the fault

Figure 3.7 Gas saturation profiles at $10^{7}$ seconds for isothermal and non-isothermal conditions

Figure 3.8 Temperature profiles for a non-isothermal version of the problem at $10^{7}$ seconds, and at the eventual steady state conditions

Figure 3.9 Enthalpy of pure $\mathrm{CO} 2$ as function of temperature and pressure, as calculated from the correlations of Altunin (1975)

Figure 4.1 Hydrostatic pressure profile prior to $\mathrm{CO} 2$ injection ..................................... 27

Figure 4.2 TOUGH2 input file for $\mathrm{CO} 2$ injection into layered brine formation ................... 28 
Figure 4.3 Time stepping and gas saturation vs. time at the wellblock for the case with 3.2 wt.- $\%$ salinity

Figure 4.4 CO2 and salt mass fractions in the aqueous phase at the wellblock for the case with $3.2 \mathrm{wt} .-\%$ salinity

Figure 4.5 Gas saturation after 2 years of $\mathrm{CO} 2$ injection for the case with 3.2 wt.-\% salinity

Figure 4.6 CO2 mass fraction dissolved in the aqueous phase after 2 years of $\mathrm{CO} 2$ injection for the case with 3.2 wt.-\% salinity

Figure 4.7 Vertical profiles of gas saturation after two years at different distances from the left boundary for the case with $3.2 \mathrm{wt} .-\%$ salinity

Figure 4.8 Vertical profiles of gas saturation at $200 \mathrm{~m}$ distance from the left boundary for the case with $3.2 \mathrm{wt} .-\%$ salinity

Figure 4.9 Vertical profiles of gas saturation at $200 \mathrm{~m}$ distance from the left boundary after 2 years

Figure B.1 Schematic of the fault zone model (a) and applied boundary conditions (b) ........ 39

Figure C.1 Schematic representation of geometry for $\mathrm{CO} 2$ injection in Utsira Formation ....... 


\section{LIST OF TABLES}

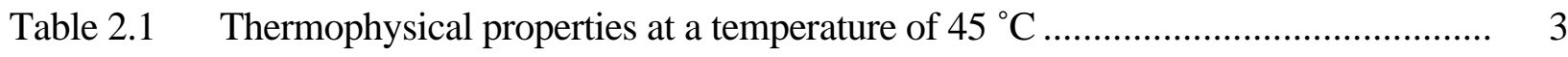

Table 3.1 PVT properties at a temperature of $45^{\circ} \mathrm{C}$ at selected pressures, as used in the TOUGH2 simulation .......................................................................... 15

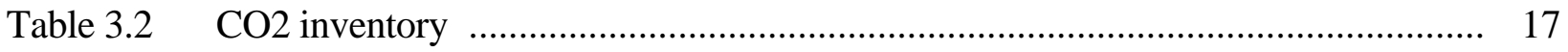

Table 4.1 Grid increments (29 blocks in $\mathrm{x}$ from left to right; 34 blocks in $\mathrm{y}$ from bottom to top) …................................................................... 24

Table 4.2 PVT properties at a temperature of $37{ }^{\circ} \mathrm{C}$ for different salinities (no CO2) .......... 24

Table 4.3 PVT properties at a temperature of $37{ }^{\circ} \mathrm{C}$ for two-phase fluid

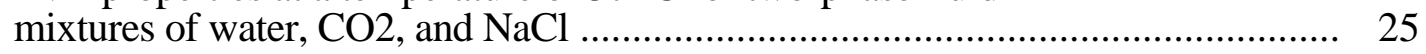

Table 4.4 CO2 mass balances (in units of $10^{6} \mathrm{~kg}$ ) for injection into fresh water and saline systems .............................................................. 34

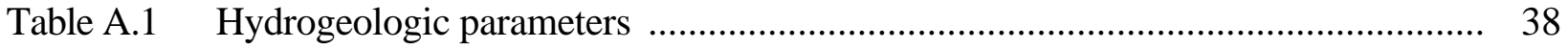

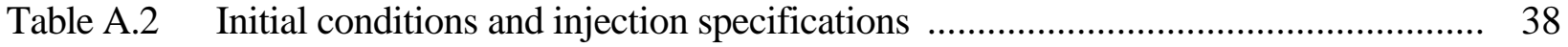

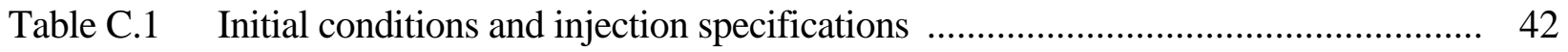

Table C.2 Hydrogeologic parameters ….............................................................. 44 


\section{Introduction}

Mathematical models and numerical simulation tools play an important role in evaluating the feasibility of geologic disposal of $\mathrm{CO} 2$, and reliable numerical simulators will be required for the design and safe operation of $\mathrm{CO} 2$ disposal facilities. The models must accurately represent the major physical and chemical processes that would be induced by injection of $\mathrm{CO} 2$ into potential disposal reservoirs. As a means of testing and evaluating numerical simulation codes we launched a code intercomparison study that featured eight prototypical simulation problems for $\mathrm{CO} 2$ disposal in saline aquifers, or oil and gas reservoirs (Pruess et al., 2000). Preliminary results of this study were presented at the Sixth International Conference on Greenhouse Gas Control Technologies (GHGT-6), held in October 2002 in Kyoto, Japan (Pruess et al., 2002a; Oldenburg et al., 2002), and a full report is available that compares results submitted by ten groups from six countries (Pruess et al., 2002b).

Here we present results obtained by LBNL for three of the numerical simulation problems in the intercomparison study that pertain to $\mathrm{CO} 2$ disposal in saline aquifers (brine formations). Our purpose is to present the simulations in greater detail than was possible in the full project report, to provide information that would be useful for benchmarking codes, and to give an expanded discussion on the behavior and dynamics of the disposal systems modeled. The analyses presented here address intercomparison problems \#3 (radial flow from a CO2 injection well), \#4 (CO2 discharge along a fault zone), and \#7 (CO2 injection into a layered brine formation). For completeness we include the problem specifications that were given in the original report in appendices. 


\section{Problem 3. Radial Flow from a $\mathrm{CO}_{2}$ Injection Well}

This is a basic problem of $\mathrm{CO}_{2}$ injection into a saline aquifer, examining two-phase flow with $\mathrm{CO} 2$ displacing (saline) water under conditions that may be encountered in brine aquifers at a depth of the order of $1.2 \mathrm{~km}$. A CO 2 injection well fully penetrates a homogeneous, isotropic, infinite-acting aquifer of $100 \mathrm{~m}$ thickness (Figure 2.1). The problem was simulated using the TOUGH2 code (Pruess et al., 1999) with an enhanced version of the EWASG fluid property module (Battistelli et al., 1997) known as ECO2 (Pruess and García, 2002). Variations are limited to two cases, namely, with and without salinity. All runs are performed in isothermal mode at $\mathrm{T}=45$ ${ }^{\circ} \mathrm{C}$ with initial pressure $\mathrm{P}=120$ bar. The numerical grid is extended to a large distance of $100 \mathrm{~km}$, so that the system would be infinite-acting for the time period simulated (10,000 days, 27.38 years). The well is modeled as a circular grid element of $\mathrm{R}=0.3 \mathrm{~m}$ into which $\mathrm{CO}_{2}$ is injected uniformly at a constant rate of $100 \mathrm{~kg} / \mathrm{s}$. Full specifications are given in Appendix A. A similar problem with slightly different specifications was recently studied by Pruess and García (2002).

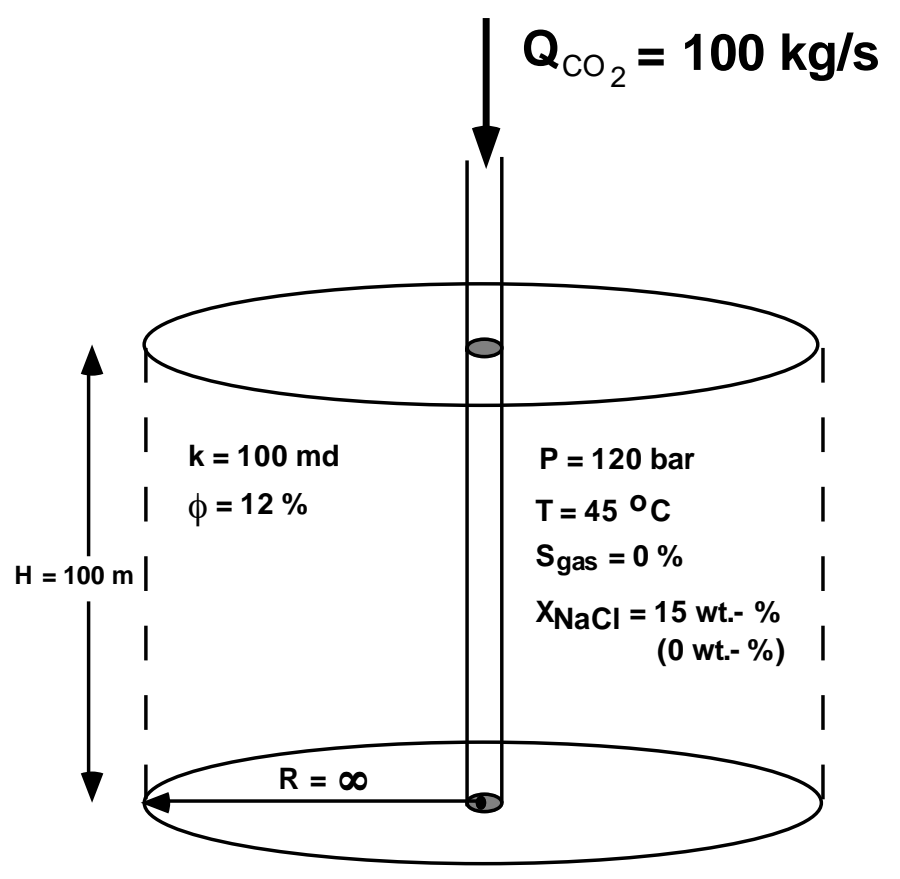

Figure 2.1 Schematic of test problem 3.

\subsection{Thermophysical Properties}

Representative fluid properties used in both simulations (with and without salinity) are given in Table 2.1. A summary of the thermophysical property model used is given in Pruess and García (2002). Pure fluid properties for water and $\mathrm{CO}_{2}$ are represented by correlations of the International Formulation Committee (1967) and Altunin (1975), respectively. Following Battistelli et al. (1997), 
Table 2.1 Thermophysical properties at a temperature of $45^{\circ} \mathrm{C}$.

\begin{tabular}{|c|c|c|c|c|}
\hline Pressure (bar) & 120 & 160 & 200 & 240 \\
\hline density $\left(\mathrm{kg} / \mathrm{m}^{3}\right)$ & 994.77 & 996.29 & 997.82 & 999.35 \\
\hline viscosity (Pa.s) & $5.97778 \mathrm{e}-4$ & $5.98341 \mathrm{e}-4$ & $5.98929 \mathrm{e}-4$ & $5.99540 \mathrm{e}-4$ \\
\hline $\begin{array}{ll}\text { water with } \mathrm{CO}_{2} & \\
& \text { density }\left(\mathrm{kg} / \mathrm{m}^{3}\right) \\
\end{array}$ & 1005.70 & 1008.14 & 1010.07 & 1011.72 \\
\hline viscosity (Pa.s) & $5.97778 \mathrm{e}-4$ & $5.98341 \mathrm{e}-4$ & $5.98929 \mathrm{e}-4$ & $5.99540 \mathrm{e}-4$ \\
\hline $\mathrm{CO}_{2}$ mass fraction & $5.1616 e-2$ & $5.6165 \mathrm{e}-2$ & $5.8304 \mathrm{e}-2$ & $5.9090 \mathrm{e}-2$ \\
\hline density $\left(\mathrm{kg} / \mathrm{m}^{3}\right)$ & 658.57 & 760.89 & 813.49 & 850.14 \\
\hline viscosity (Pa.s) & $5.16820 \mathrm{e}-5$ & $6.56320 \mathrm{e}-5$ & $7.45049 \mathrm{e}-5$ & $8.15659 \mathrm{e}-5$ \\
\hline water mass fraction & $9.93985 \mathrm{e}-5$ & $8.60323 e-5$ & $8.04694 \mathrm{e}-5$ & $7.70001 \mathrm{e}-5$ \\
\hline $\begin{array}{r}\text { brine }(\text { water }+\mathbf{1 5} \text { wt. } \% \mathbf{~ N a C l}) \\
\text { density }\left(\mathrm{kg} / \mathrm{m}^{3}\right)\end{array}$ & 1100.00 & 1101.53 & 1103.07 & 1104.61 \\
\hline viscosity (Pa.s) & $8.28519 \mathrm{e}-4$ & $8.29299 \mathrm{e}-4$ & $8.30113 \mathrm{e}-4$ & $8.30961 \mathrm{e}-4$ \\
\hline density $\left(\mathrm{kg} / \mathrm{m}^{3}\right)$ & 1103.54 & 1105.36 & 1107.01 & 1108.57 \\
\hline viscosity (Pa.s) & $8.28519 \mathrm{e}-4$ & $8.29299 \mathrm{e}-4$ & $8.30113 e-4$ & $8.30961 \mathrm{e}-4$ \\
\hline $\mathrm{CO}_{2}$ mass fraction & $2.5234 \mathrm{e}-2$ & $2.7494 \mathrm{e}-2$ & $2.8558 \mathrm{e}-2$ & $2.8950 \mathrm{e}-2$ \\
\hline
\end{tabular}

aqueous phase (brine) density is calculated as a function of temperature, pressure and salinity from a correlation given by Phillips et al. (1981). Halite $(\mathrm{NaCl})$ solubility is calculated from an equation due to Potter quoted in Chou (1987), and salinity effects on vapor pressure are represented with a correlation due to Haas (1976). $\mathrm{CO}_{2}$ dissolution in aqueous phase is modeled using an extended version of Henry's law that includes a fugacity coefficient and a Poynting correction factor. Henry's coefficient is a function of temperature and mole fraction of salt dissolved in the aqueous phase. Water partitioning into the gas phase is modeled as an evaporation process (see additional details in section 3.1). Changes in aqueous phase density from $\mathrm{CO}_{2}$ dissolution have a small impact on simulated system behavior, but were included using a correlation developed by García (2001). No allowance is presently made for dependence of aqueous phase viscosity on dissolved $\mathrm{CO}_{2}$. 


\section{2 $\mathrm{CO}_{2}$ Injection into an Aquifer without Salinity}

Figure 2.2 shows the evolution of the gas saturation front up to a time of 10,000 days. An important advantage of the radial flow problem considered here is that it admits a similarity solution. Specifically, the solution depends on radial distance $\mathrm{R}$ and time $\mathrm{t}$ only through the similarity variable $\xi=\mathrm{R}^{2} / \mathrm{t}$, even when taking into account all the non-linearities due to PVT properties and two-phase flow (O’Sullivan, 1981; Doughty and Pruess, 1992). The space and time discretization employed for finite difference simulation will violate the rigorous $\mathrm{R}^{2} / \mathrm{t}$ invariance, so that the similarity property will be maintained only approximately. Accuracy of the numerical simulation can be checked by plotting the results as a function of the similarity variable $R^{2} / t$. Figure 2.3 shows the results for pressure as a function of the similarity variable. Simulated results are presented for four different times $(\mathrm{t}=30,100,1000,10000$ days $)$ and two fixed locations $(\mathrm{R}=$ $25.25,1011 \mathrm{~m})$. The agreement is good, confirming the approximate preservation of the similarity property in the numerical solution. Figures 2.4 and 2.5 show simulated results for gas saturation and dissolved $\mathrm{CO}_{2}$ mass fraction as a function of the similarity variable. Gas saturation results show three distinct regions emerging from the $\mathrm{CO}_{2}$ injection process. The first region with $\mathrm{R}^{2} / \mathrm{t} \leq$ $5 \times 10^{-7} \mathrm{~m}^{2} / \mathrm{s}$ corresponds to a zone where complete dry-out of aqueous phase has occurred. This region is followed by an intermediate region extending to $\mathrm{R}^{2} / \mathrm{t} \approx 10^{-2} \mathrm{~m}^{2} / \mathrm{s}$ where liquid and gas phases coexists. Finally, there is an outer region with $\mathrm{R}^{2} / \mathrm{t} \geq 10^{-2} \mathrm{~m}^{2} / \mathrm{s}$ in which single-phase liquid conditions prevail. The TOUGH2 input file used for the simulation is shown in Figure 2.6.

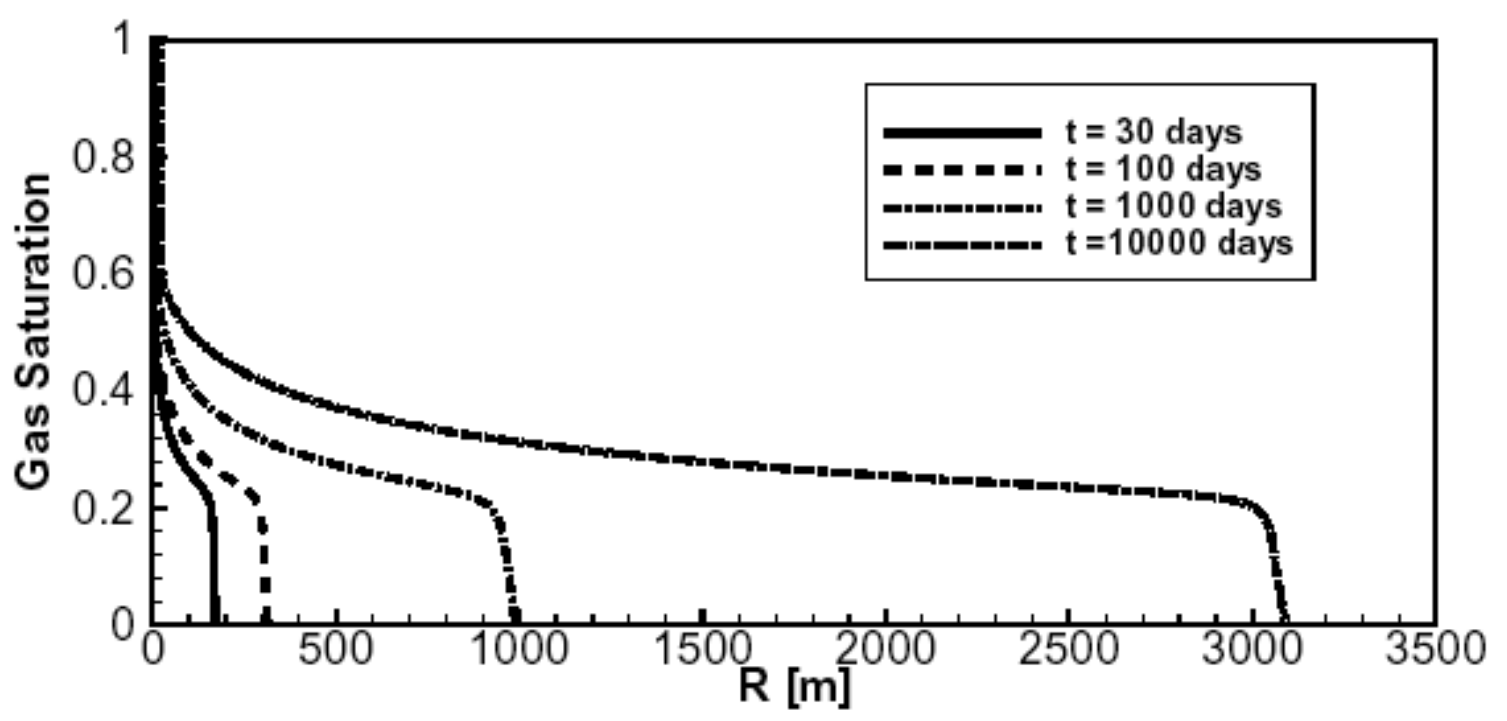

Figure 2.2 Simulated gas saturation front (no salinity). 


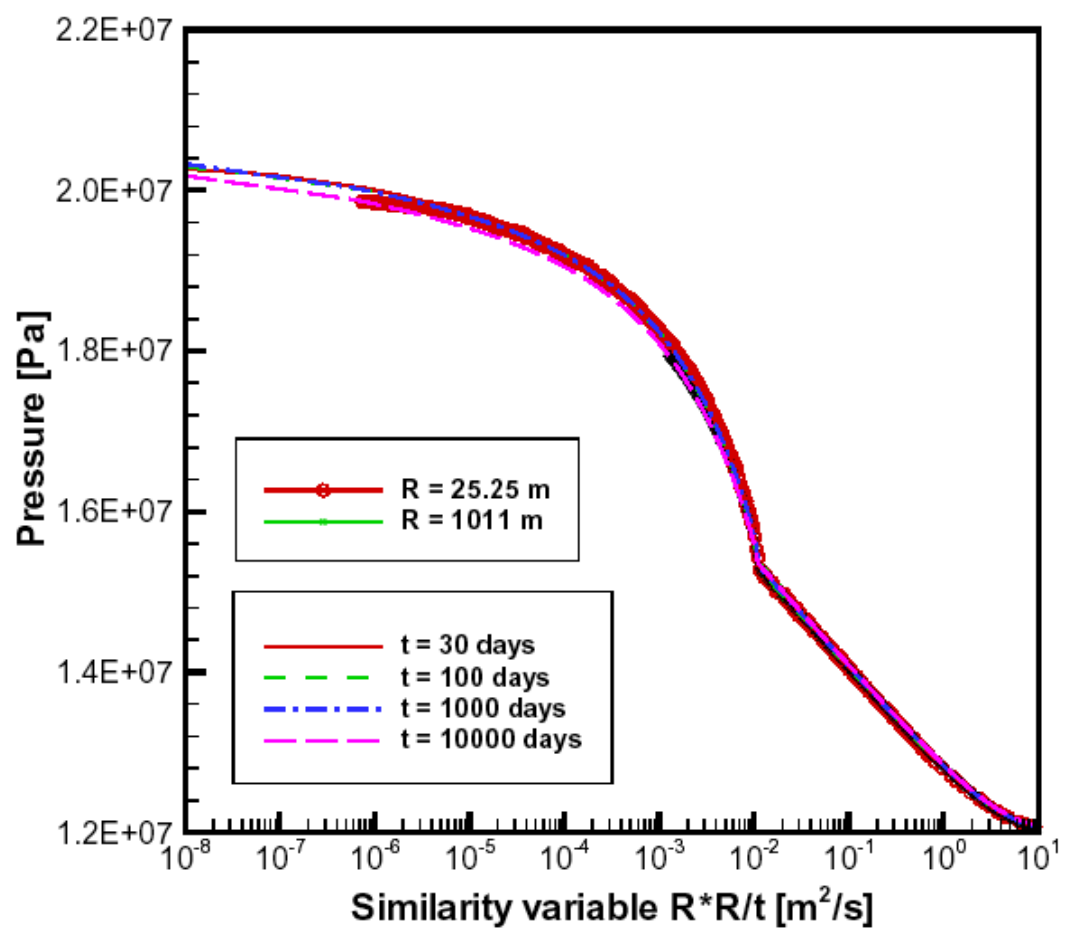

Figure 2.3 Simulated pressure (no salinity).

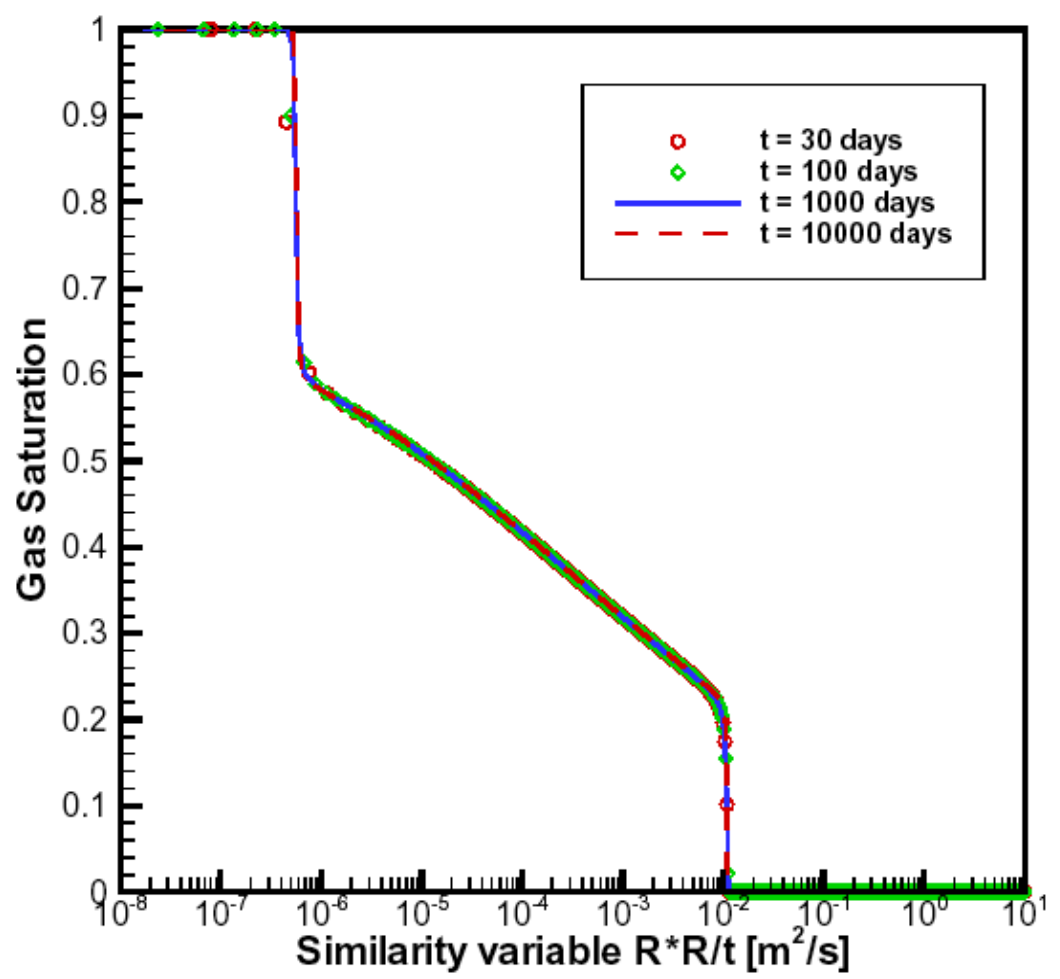

Figure 2.4 Simulated gas saturation (no salinity). 


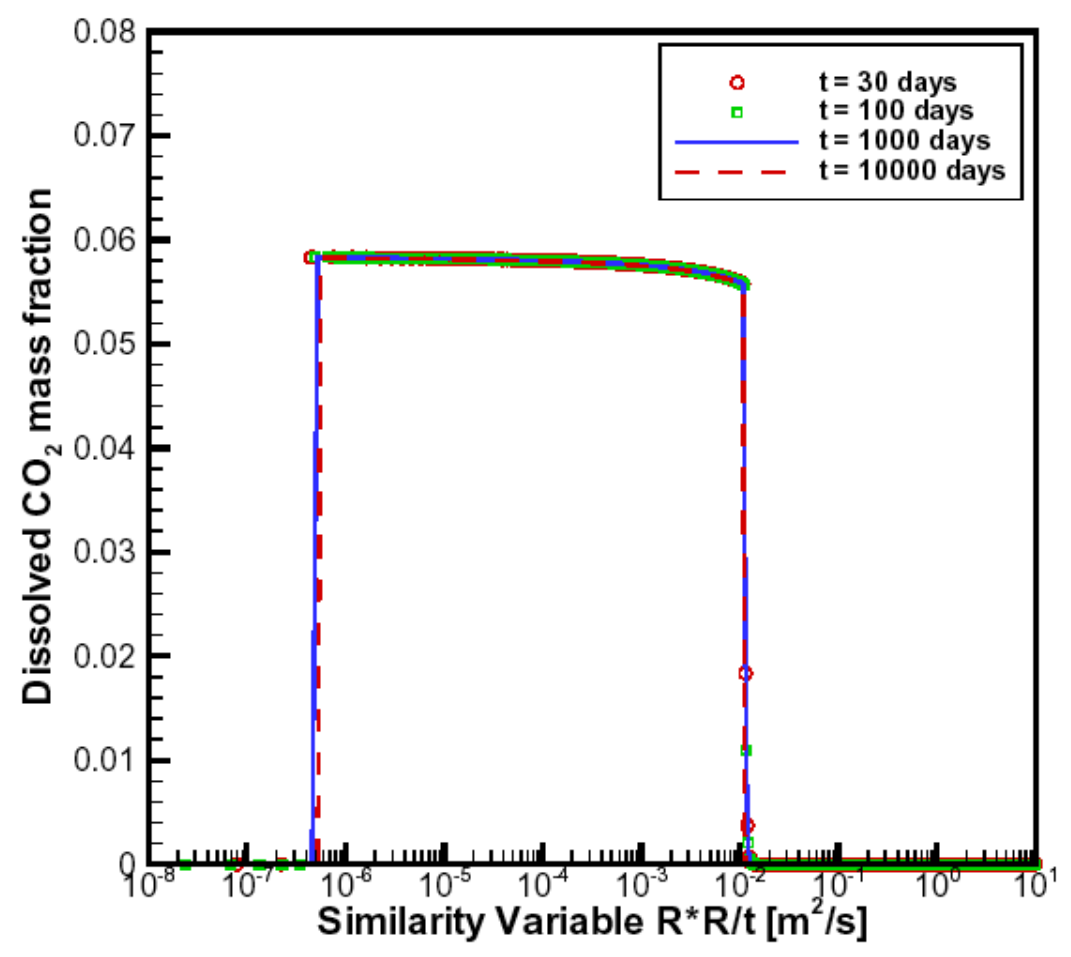

Figure 2.5 Simulated dissolved $\mathrm{CO}_{2}$ mass fraction (no salinity). 


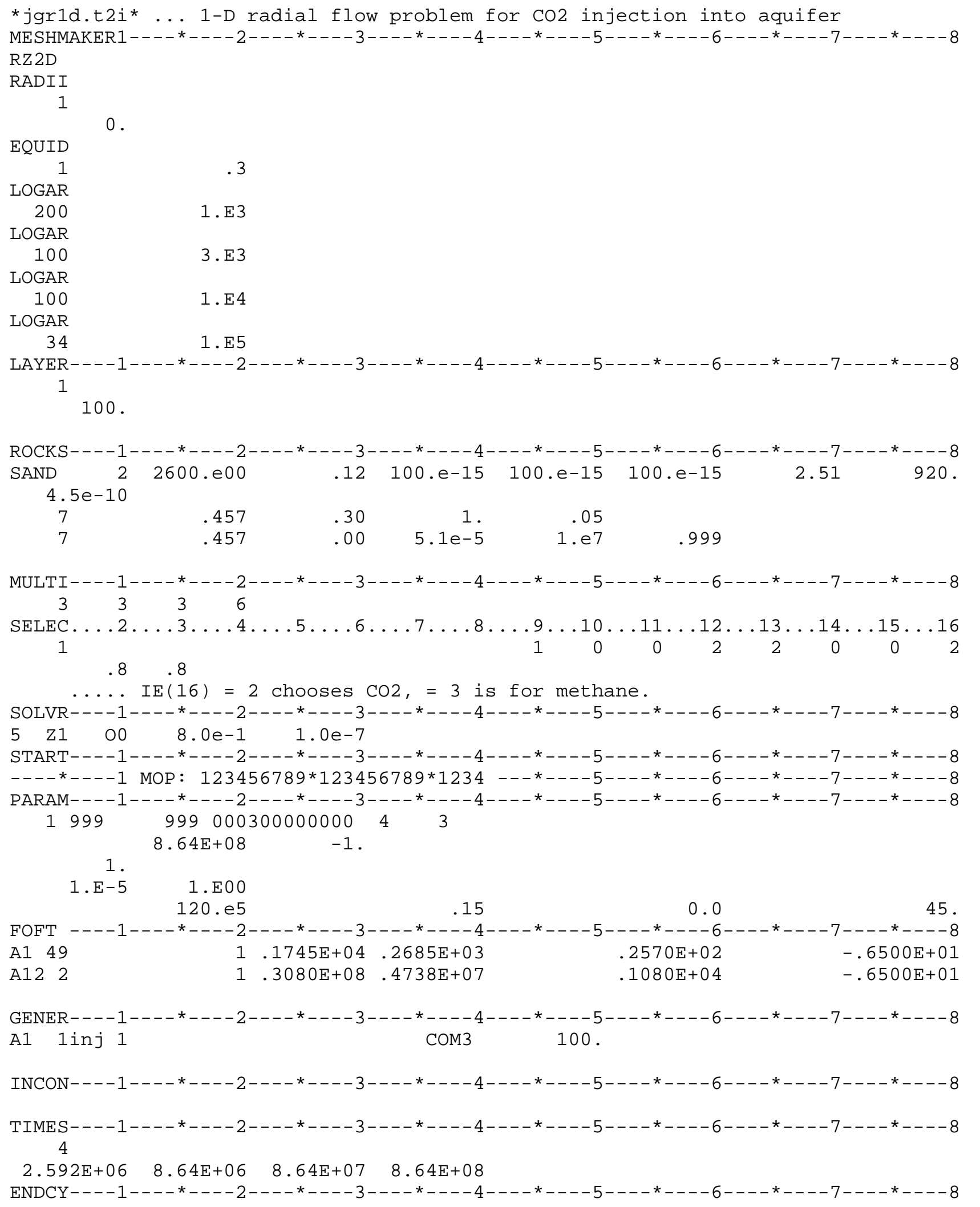

Figure 2.6 TOUGH2 input file for the radial flow problem. 


\section{3 $\mathrm{CO}_{2}$ Injection into a Saline Aquifer}

The presence of salt in the system induces additional processes, particularly salt precipitation near the injection well. The volume fraction of precipitated salt in the original pore space $\phi_{0}$ is termed "solid saturation", and denoted by $S_{\mathrm{s}}$. A fraction $\phi_{0} S_{\mathrm{S}}$ of reservoir volume is occupied by precipitate, while the remaining void space $\phi_{\mathrm{f}}=\phi_{0}\left(1-\mathrm{S}_{\mathrm{S}}\right)$ is available for fluid phases; $\phi_{\mathrm{f}}$ is referred to as "active flow porosity." The reduction of pore space reduces the permeability of the medium. The current version of ECO2 inherited the models for permeability reduction from the EWASG module (Battistelli et al., 1997) of which it is a descendant. The change of permeability due to porosity reduction is a complex process and a variety of models have been proposed in the literature (Verma and Pruess, 1988; Pape et al., 1999). To facilitate the comparison of the results presented here with other codes, the permeability reduction capability implemented in ECO2 was turned off. Nevertheless one must be aware of the possible implications of this simplification. A similar simulation presented in Pruess and García (2002) showed that a modest amount of precipitation of $\mathrm{S}_{\mathrm{S}}=2 \%$ produced a reduction in permeability of $18 \%$.

Simulated results (Figs. 2.7, 2.8, 2.9) show that the overall behavior is very similar to the simulation run without salinity. As expected, the three distinct regions developed during $\mathrm{CO}_{2}$ injection occur at about the same $\mathrm{R}^{2} / \mathrm{t}$ locations. A $10 \%$ higher pressure buildup occurs in the vicinity of the injection well, due to the larger viscosity of brine as compared to fresh water. Comparing Fig. 2.9 with Fig. 2.5 it is seen that the dissolution of $\mathrm{CO}_{2}$ in the aqueous phase is reduced by $50 \%$ due to salinity effects ("salting out").

The figures for pressure, saturation and dissolved $\mathrm{CO}_{2}$ mass fraction demonstrate that the similarity property is well maintained. The results for solid saturation show considerable scatter at small values of $\mathrm{R}^{2} / \mathrm{t}$ where discretization errors are significant (Fig. 2.10). Salt precipitation occurs only in the vicinity of the injection well (first 20 meters). In order to reduce discretization errors when calculating solid salt saturation, we performed another simulation with a finer grid, using small increments of constant $\Delta \mathrm{R}=0.05 \mathrm{~m}$ near the injection point. This prevents large jumps in solid saturation at elements near the injection well, and provides excellent preservation of the similarity property (Fig. 2.11). 


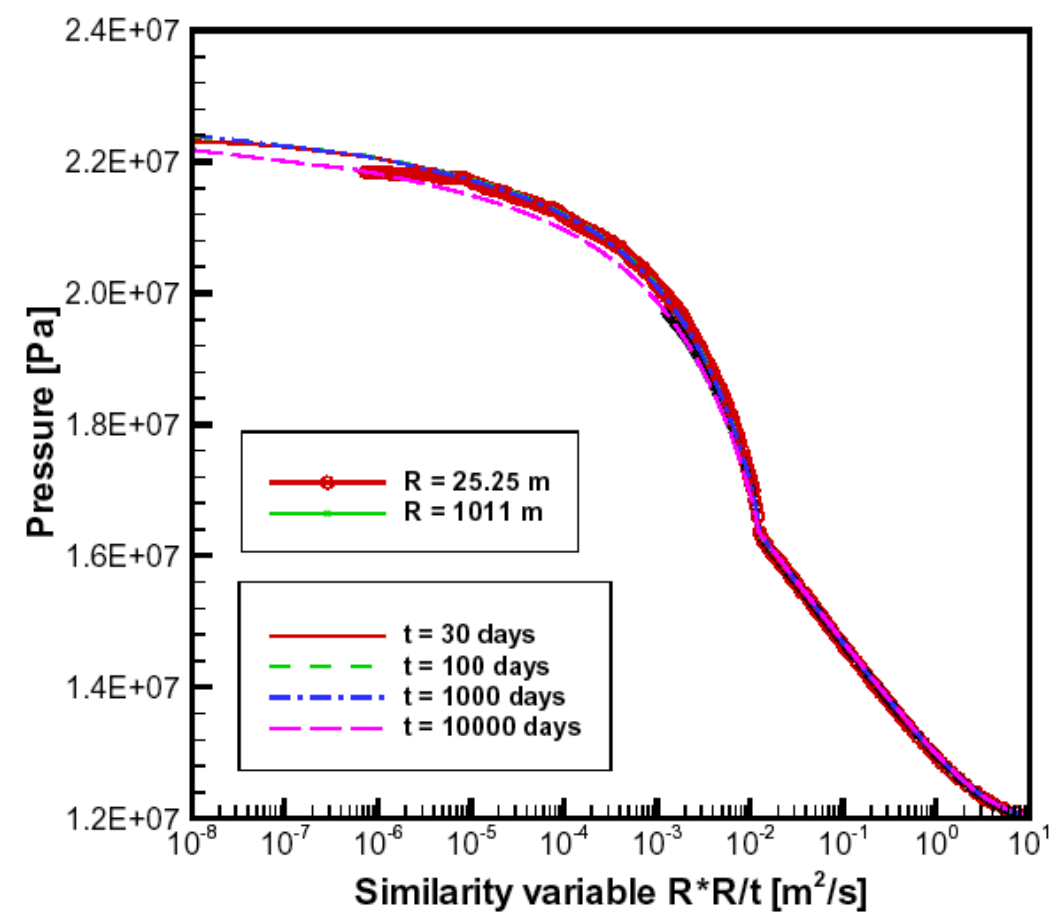

Figure 2.7 Simulated pressure (15 wt.-\% salinity).

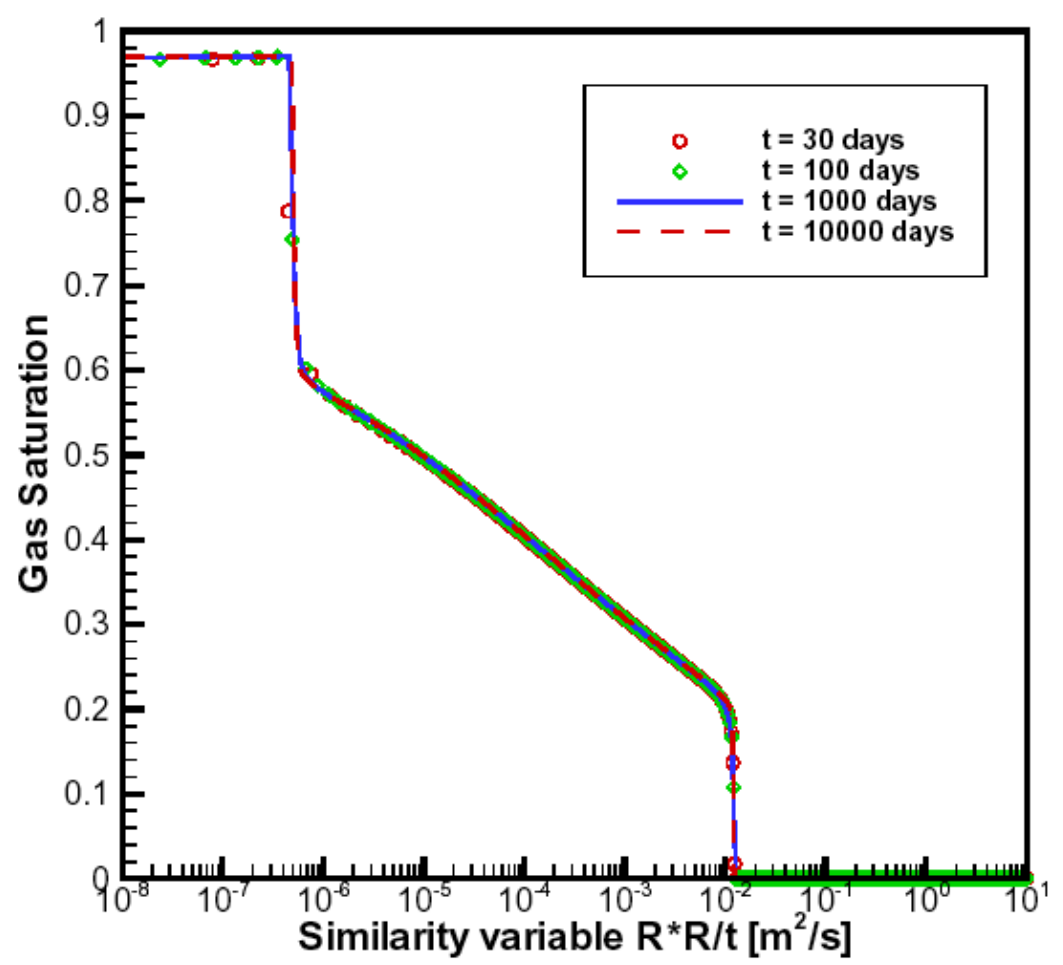

Figure 2.8 Simulated gas saturation (15 wt.-\% salinity). 


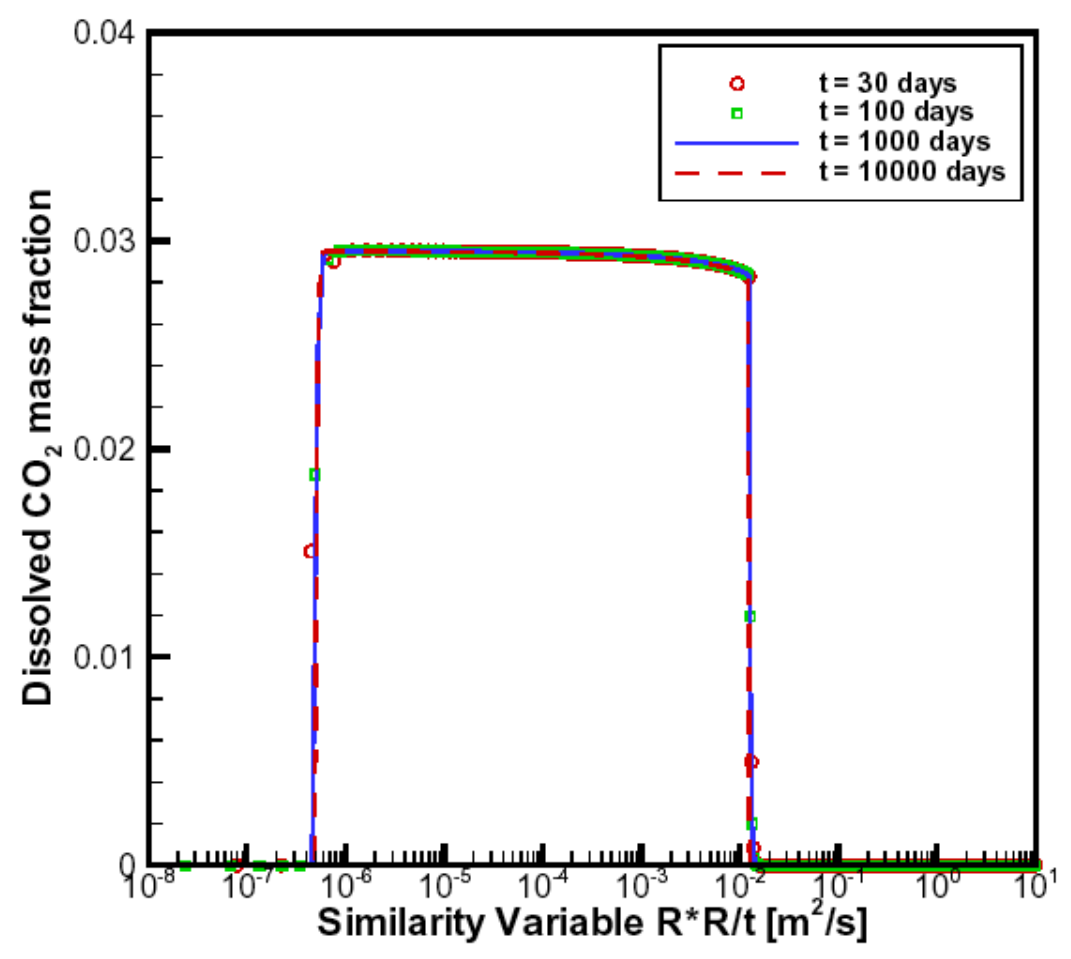

Figure 2.9 Simulated dissolved $\mathrm{CO}_{2}$ mass fraction (15 wt.-\% salinity).

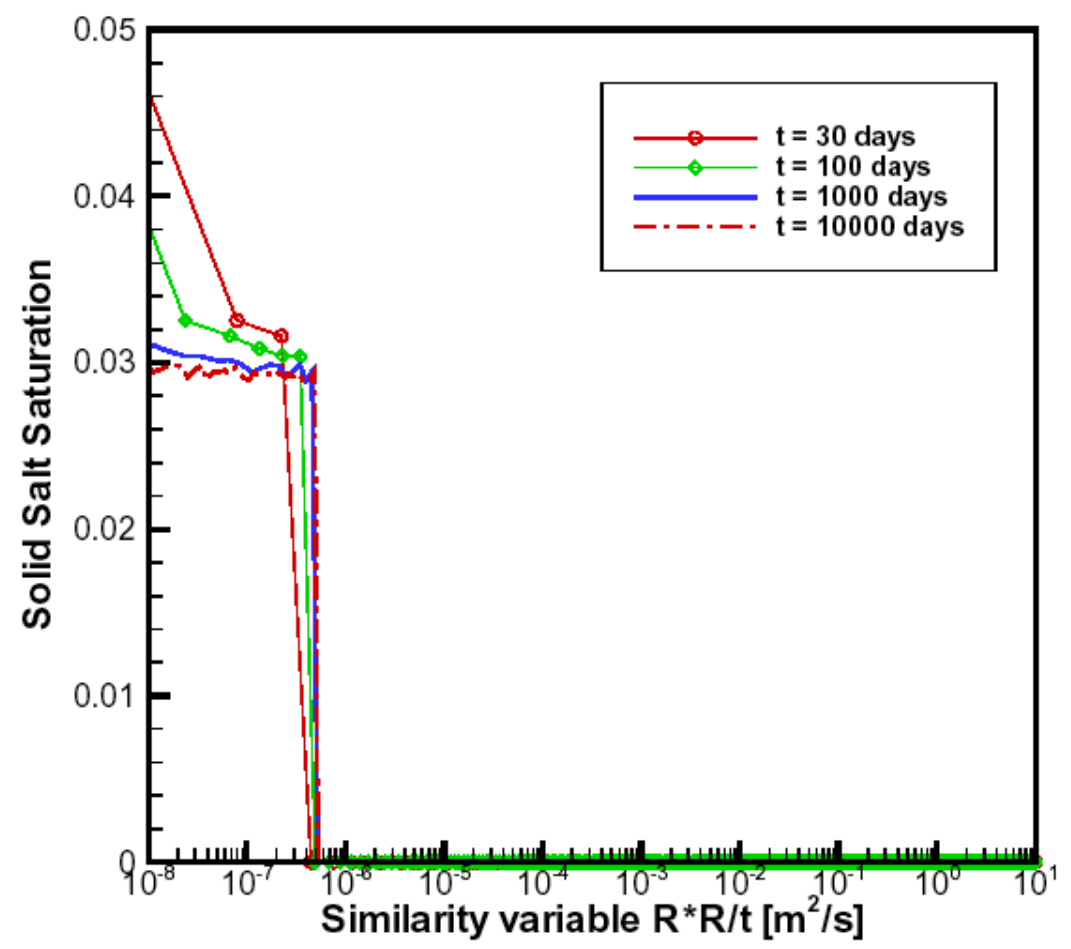

Figure 2.10 Simulated solid salt saturation (15 wt.-\% salinity). 


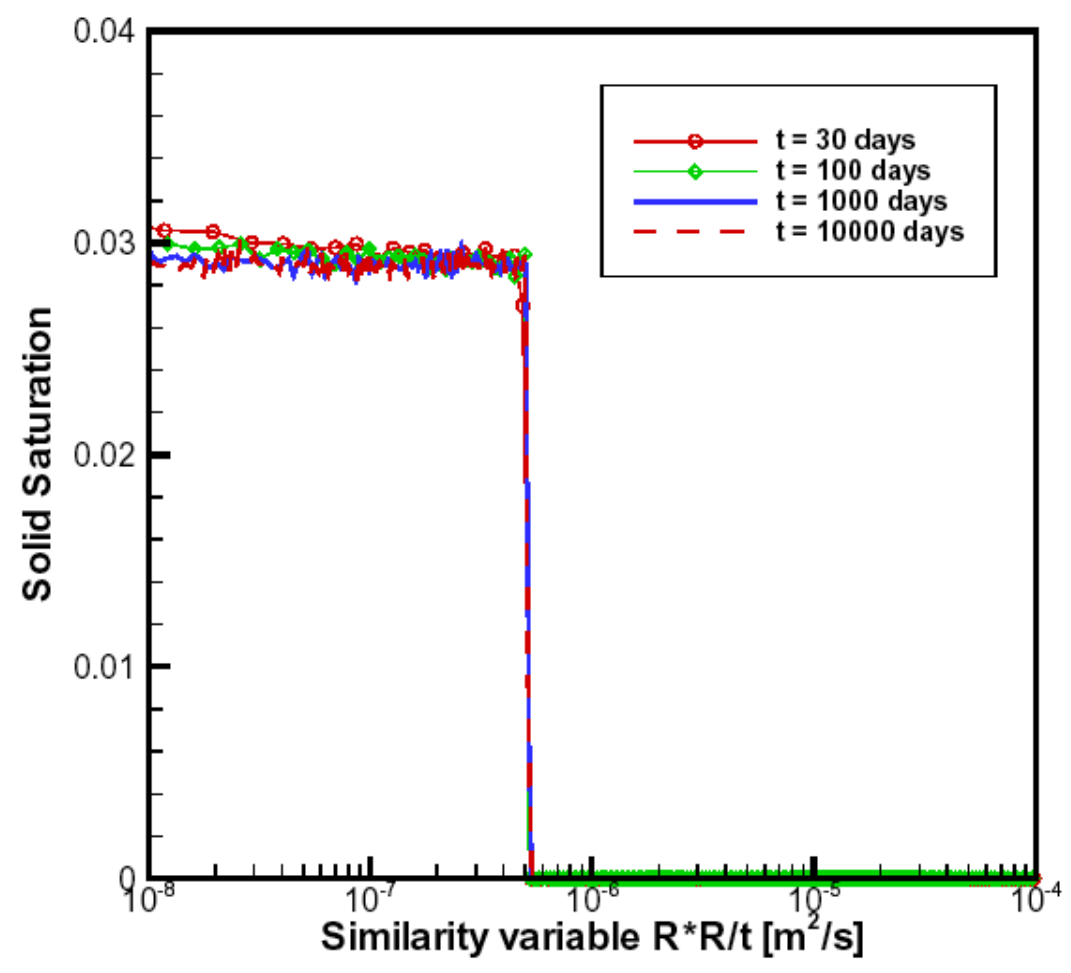

2.11 Simulated solid salt saturation using a finer grid near the injection well. 


\section{Problem 4. CO2 Discharge Along a Fault Zone}

The amounts of $\mathrm{CO} 2$ that would need to be disposed of at fossil-fueled power plants are very large. A coal-fired plant with a capacity of 1,000 MWe generates approximately 30,000 tonnes of $\mathrm{CO} 2$ per day (Hitchon 1996). When disposed of into brine formations, $\mathrm{CO} 2$ injection plumes would over time extend to large distances of the order of ten kilometers or more, making it likely that geologic discontinuities such as faults and fractures will be encountered, with an associated potential for $\mathrm{CO} 2$ losses from the primary disposal aquifer. $\mathrm{CO} 2$ leaks through caprock discontinuities have a potential for self-enhancement, because pressures can actually decrease and/or flow rates increase as escaping $\mathrm{CO} 2$ creates a pathway towards shallower strata. It may be possible for a runaway process to develop where an initially "small" leak may accelerate to the point of a catastrophic, eruptive failure of a $\mathrm{CO} 2$ disposal system, that could result in major $\mathrm{CO} 2$ discharge and damage at the land surface (Pruess and García, 2002).

Migration of $\mathrm{CO} 2$ along a water-saturated fault zone would be subject to gravitational and viscous instabilities, and would likely involve complex two- and three-dimensional flow effects. As a first approximation to this kind of problem, we consider here a highly simplified situation in which a potential CO2 leakage path is modeled as a 1-D column (Fig. 3.1). Problem specifications are given in Appendix B.

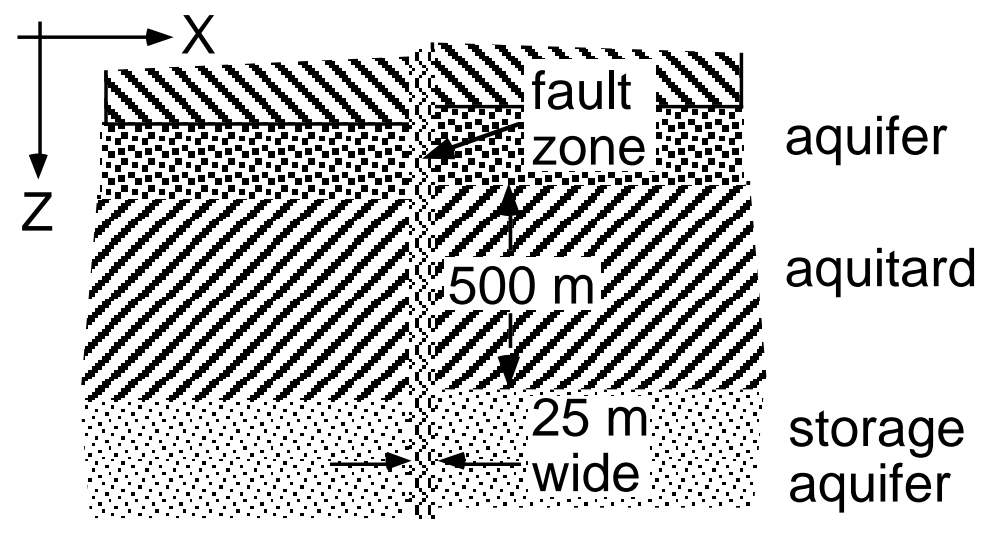

(a)

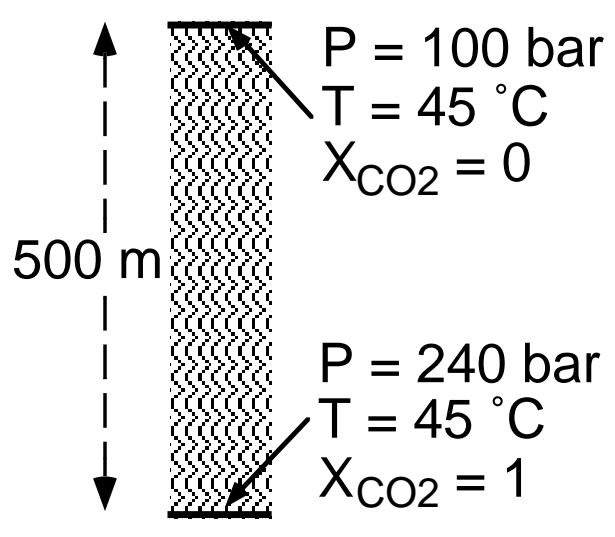

(b)

Figure 3.1 Schematic of the fault zone model (a) and applied boundary conditions (b).

This problem was simulated with the TOUGH2 code (Pruess et al., 1999), using an enhanced version of the EWASG fluid property module (Battistelli et al., 1997) known as "ECO2" (Pruess and García, 2002). The problem is run in two segments. A first run segment obtains gravity equilibrium relative to a pressure of 100 bar prescribed at the top boundary. The gravity-equilibrated conditions obtained are used as initial conditions in a second run segment, where conditions of $\mathrm{P}=240$ bar and $\mathrm{X}_{\mathrm{CO} 2}=1$ are maintained at the lower boundary. All runs are 
performed for pure water (no salinity) in isothermal mode at $\mathrm{T}=45^{\circ} \mathrm{C}$. A length of $1 \mathrm{~m}$ of fault zone is simulated and a constant vertical grid spacing of $5 \mathrm{~m}$ is specified. The TOUGH2 input file for the problem is shown in Fig. 3.2.

\subsection{Thermophysical Properties}

Representative fluid properties used in the simulation are given in Table 3.1. Water properties are represented, within experimental uncertainty, by the steam table equations published by the International Formulation Committee (1967). Properties of pure CO2 are obtained from the correlations of Altunin (1975), as implemented in a computer program kindly provided to us by V.I. Malkovsky of IGEM, Moscow (private communication, 1999). The Altunin correlations are used to tabulate $\mathrm{CO} 2$ density and viscosity vs. temperature and pressure, with increments of $\Delta \mathrm{T}=2{ }^{\circ} \mathrm{C}, \Delta \mathrm{P}$ $=4$ bar. During a simulation TOUGH2 performs interpolation from these tables. CO2 dissolution in the aqueous phase is modeled with an extended version of Henry's law that includes fugacity effects (Spycher and Reed, 1988) and a Poynting correction for CO2 solubility (Prausnitz et al., 1986), with a molar volume of $32.1 \mathrm{~cm}^{3} /$ mole (Spycher et al., 2002). No allowance is presently made for changes in water density and viscosity from $\mathrm{CO} 2$ dissolution. Water partitioning into the $\mathrm{CO} 2$-rich (gas) phase is modeled as an evaporation process, as follows. In two-phase conditions, water partial pressure in the gas phase is assumed equal to saturated vapor pressure, $P_{V}=P_{s a t}(T)$, and additivity of pressures is assumed so that $\mathrm{P}_{\mathrm{gas}}=\mathrm{P}_{\mathrm{CO} 2}+\mathrm{P}_{\mathrm{v}}$. This model underestimates the (small) water content of the gas phase; a more accurate correlation has recently been developed but has not yet been implemented into TOUGH2/ECO2 (Spycher et al., 2002). A summary of the thermophysical property model used here is given in Pruess and García (2002).

\subsection{Gravity Equilibration}

Pore compressibility is set to 0 in this part of the simulation, so that porosity remains a constant $35 \%$ throughout as fluid pressures change. A tight convergence tolerance of RE1 = 1.e-10 is used. After 22 time steps and a simulation time of $\mathrm{t}=4.72 \times 10^{9}$ seconds an accurate hydrostatic

equilibrium is obtained, with maximum pore velocities of $2 \times 10^{-19} \mathrm{~m} / \mathrm{s}$. Pressure in the lowest grid block, $2.5 \mathrm{~m}$ above the lower boundary, is computed as 148.56 bar. 


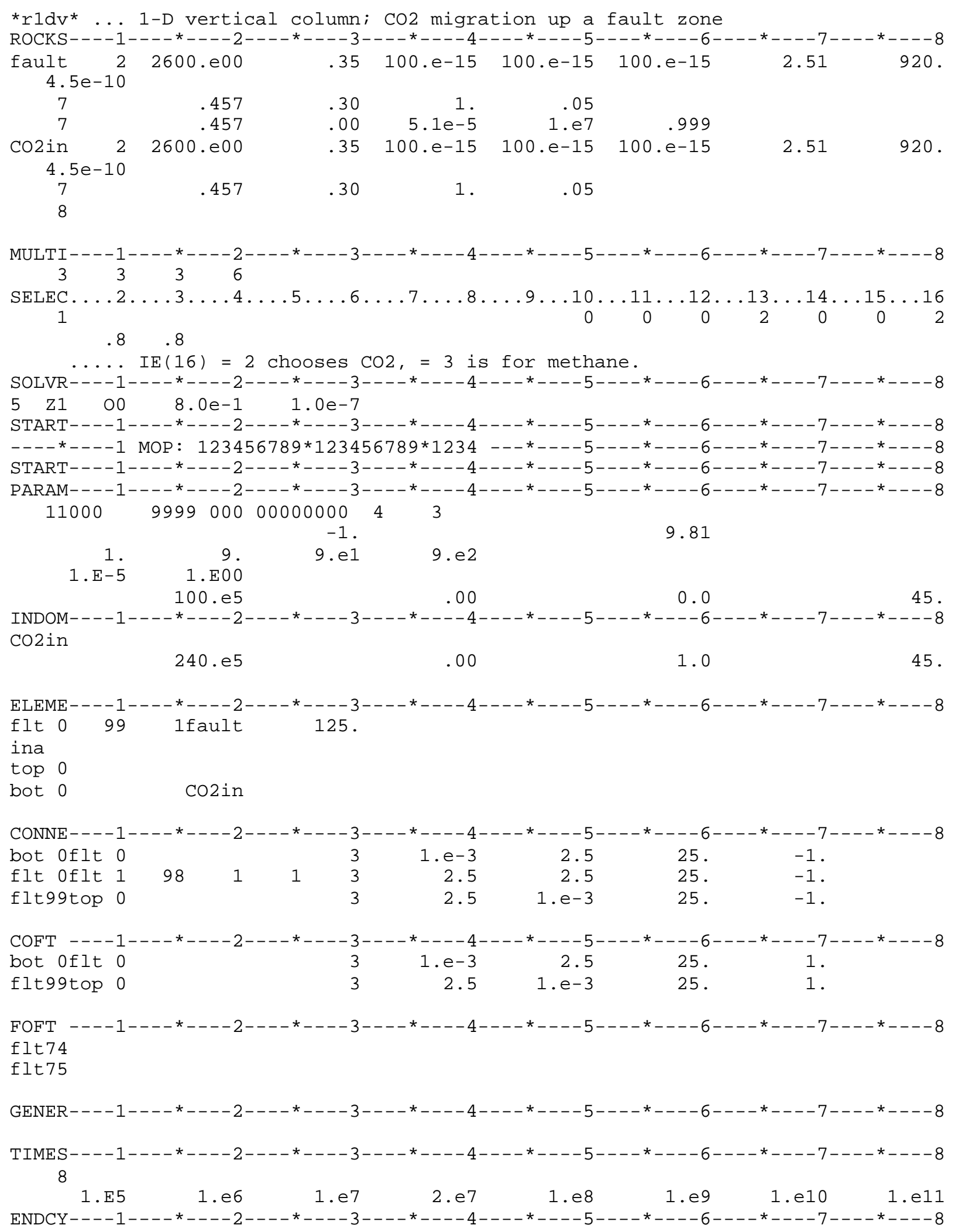

Figure 3.2 TOUGH2 input file for fault zone problem. 
Table 3.1. PVT properties at a temperature of $45^{\circ} \mathrm{C}$ at selected pressures, as used in the TOUGH 2 simulation.

\begin{tabular}{|c|c|c|c|c|}
\hline $\begin{array}{ll}\text { fluid phase } & \mathrm{P}(\mathrm{bar})\end{array}$ & 120 & 160 & 200 & 240 \\
\hline $\begin{array}{l}\text { pure water } \\
\qquad \text { density }(\mathrm{kg} / \mathrm{m} 3)\end{array}$ & 994.768 & 996.292 & 997.821 & 999.354 \\
\hline viscosity (Pa s) & $5.97778 \mathrm{e}-4$ & $5.98341 \mathrm{e}-4$ & $5.98929 \mathrm{e}-4$ & $5.99540 \mathrm{e}-4$ \\
\hline $\begin{array}{l}\text { water with CO2 } \\
\text { density }(\mathrm{kg} / \mathrm{m} 3)\end{array}$ & 994.768 & 996.292 & 997.821 & 999.354 \\
\hline viscosity (Pa s) & $5.97778 \mathrm{e}-4$ & $5.98341 \mathrm{e}-4$ & $5.98929 \mathrm{e}-4$ & $5.99540 \mathrm{e}-4$ \\
\hline $\mathrm{CO} 2$ mass fraction & $5.22541 \mathrm{e}-2$ & $5.70921 \mathrm{e}-2$ & $5.95094 \mathrm{e}-2$ & $6.05605 \mathrm{e}-2$ \\
\hline density $(\mathrm{kg} / \mathrm{m} 3)$ & 658.574 & 760.891 & 813.493 & 850.145 \\
\hline viscosity (Pa s) & $5.16820 \mathrm{e}-5$ & $6.56320 \mathrm{e}-5$ & $7.45049 \mathrm{e}-5$ & $8.15659 \mathrm{e}-5$ \\
\hline water mass fraction & $9.93985 e-5$ & $8.60323 e-5$ & $8.04694 \mathrm{e}-5$ & $7.70001 \mathrm{e}-5$ \\
\hline
\end{tabular}

\subsection{CO2 Displacement}

Capillary pressure parameters were adjusted so that maximum Pcap is $10^{7} \mathrm{~Pa}$, and Pcap vanishes for small gas saturations of $S_{g} \leq 0.001$. These and other simulation parameters can be seen from the TOUGH2 input deck, Fig. 3.2.

The simulated evolution of the system proceeds through four stages (Fig. 3.3). In stage 1, $\mathrm{CO} 2$ enters the first grid block above the lower boundary, evolving a gas phase there and causing rapid pressurization that migrates up the fault. Stage 1 ends at approximately $10^{4}$ seconds when the pressure pulse reaches the top of the fault, causing outflow of water to commence. During the subsequent stage 2 the $\mathrm{CO} 2$ displacement front migrates up the fault until, after about $3 \times 10^{7}$ seconds, the front reaches the top. At this time $\mathrm{CO} 2$ discharge from the fault begins, while water discharge declines to small values because capillary effects reduce the effective pressure gradient for the aqueous phase at the top of the fault. Stage 3 lasts from $3 \times 10^{7}$ to $2 \times 10^{10}$ seconds, and is characterized by single-phase gas outflow from the fault. Water continues to be removed by evaporation into the flowing gas phase, causing gas relative permeabilities and flow rates to increase. As gas saturations increase capillary pressures get stronger, and at $1.16 \times 10^{10}$ seconds the effective pressure gradient for the aqueous phase at the top of the fault reverses, leading to downflow of water from the top boundary at very small rates. Eventually the entire flow system 
dries out, and in stage 4 we have a steady single-phase gas flow up the fault. TOUGH2 recognizes a steady state, and the simulation terminates after 486 time steps and a simulation time of $2.552 \times 10^{13}$ seconds.

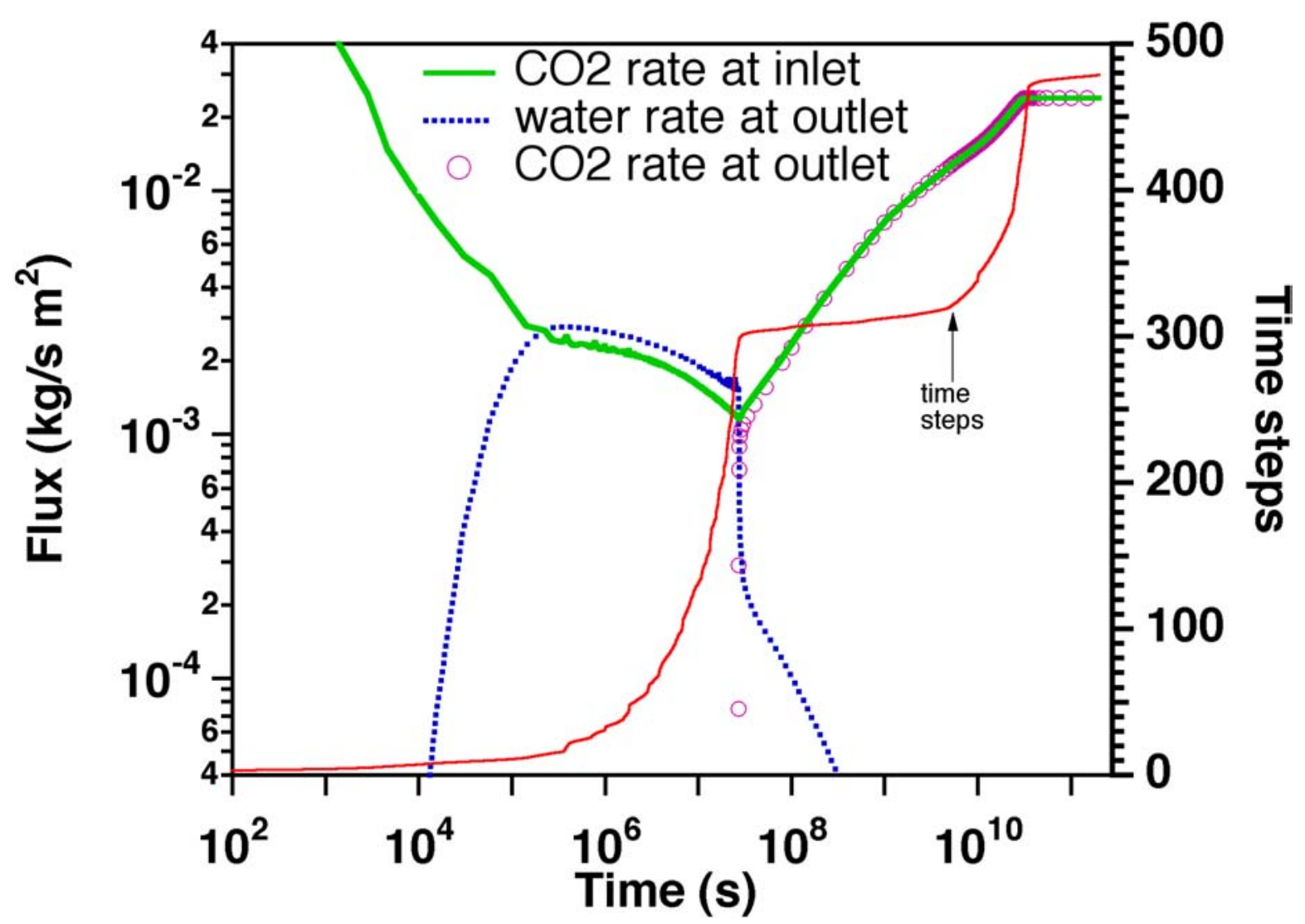

Figure 3.3 Simulated results for fluxes and time steps versus time.

Simulation progress and time stepping reflect non-linearities of the flow processes. Many relatively small time steps are required toward the end of stage 2 as the two-phase front approaches the upper boundary (Fig. 3.3). Smaller time steps again occur towards the end of stage 3 when the dryout front approaches the top boundary.

Profiles of gas saturations and $\mathrm{CO} 2$ mass fractions dissolved in the aqueous phase are shown in Fig. 3.4 at times of $10^{7}$ and $2 \times 10^{7}$ seconds. Dissolved CO2 mass fractions range from $5.5 \%$ near the top of the two-phase zone to $6 \%$ near the bottom of the fault. Fugacity and Poynting corrections for $\mathrm{CO} 2$ dissolution have very substantial effects; without such corrections, dissolved $\mathrm{CO} 2$ mass fraction would be in excess of $18 \%$. Pressure profiles at times of $10^{7}$ and $2 \times 10^{7}$ seconds are given in Fig. 3.5. The change in slope marks the transition from two-phase conditions below to single-phase conditions above. The pressure gradient in the two-phase zone is 
larger than in the single-phase region, indicating that mobility loss from relative permeability effects dominates over mobility gain from the lower viscosity of $\mathrm{CO} 2$ as compared to water. Results for the simulated $\mathrm{CO} 2$ inventory of the system at $\mathrm{t}=10^{7}$ and $2 \times 10^{7}$ seconds are given in Table 3.2.

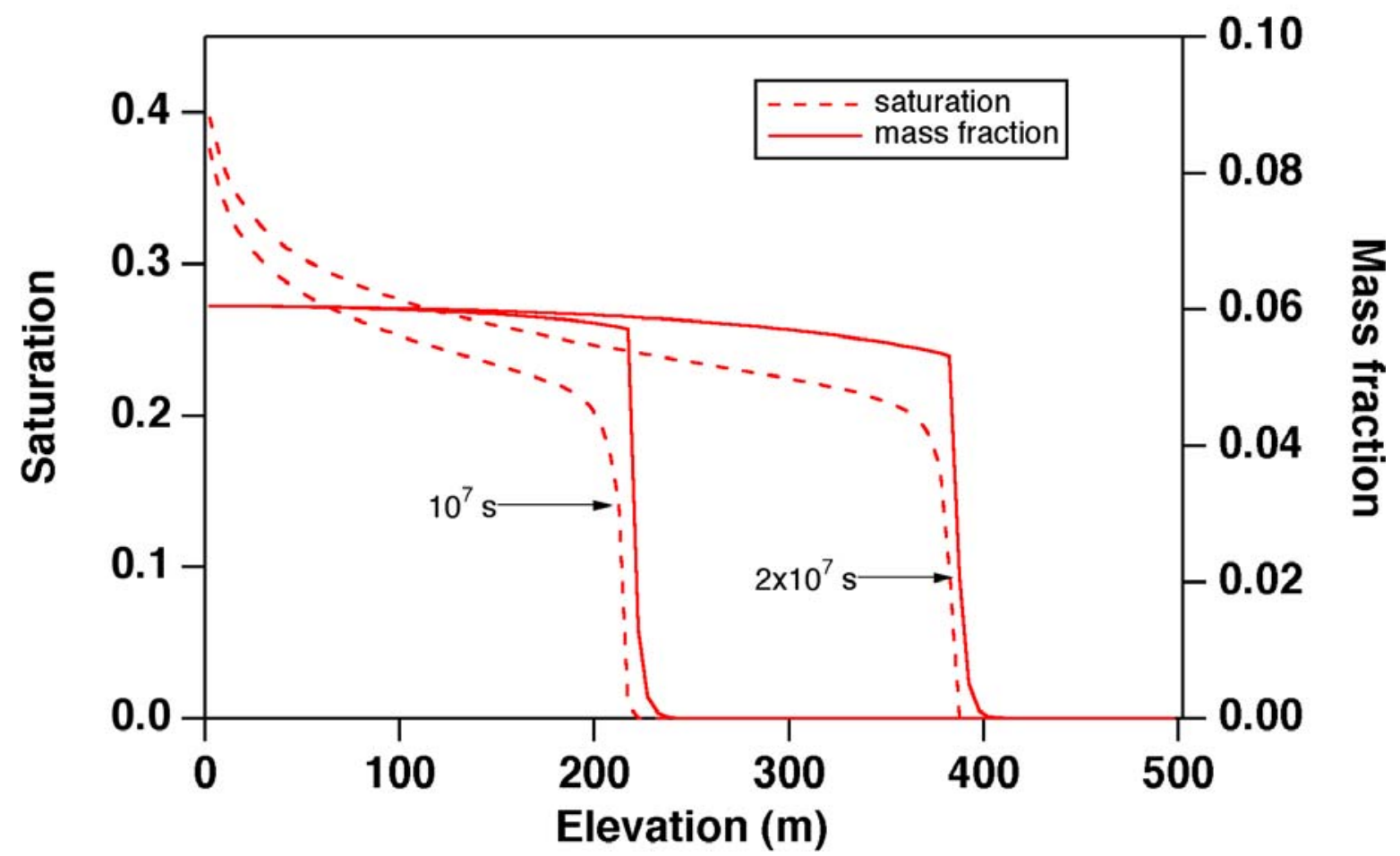

Figure 3.4 Gas saturation and dissolved $\mathrm{CO} 2$ mass fractions at times of $10^{7}$ and $2 \times 10^{7}$ seconds.

Table 3.2. CO2 inventory.

\begin{tabular}{|l|l|l|}
\hline & $10^{7}$ seconds & $2 \times 10^{7}$ seconds \\
\hline gas phase & 396.706 tonnes & 690.489 tonnes \\
\hline liquid phase & 86.795 tonnes & 147.934 tonnes \\
\hline total & 483.502 tonnes & 838.424 tonnes \\
\hline
\end{tabular}

\subsection{Numerical Artifacts}

Fig. 3.6 shows the transient evolution of pressures and gas saturations at a monitoring grid block that is located at an elevation of $372.5 \mathrm{~m}$ up the fault. Pressures are seen to go through rapid variations as the grid block makes a transition from single-phase to two-phase conditions. The pressure transients are mostly spurious effects that arise from space discretization and can be understood as follows. As long as the monitoring block remains in single-phase conditions, all 


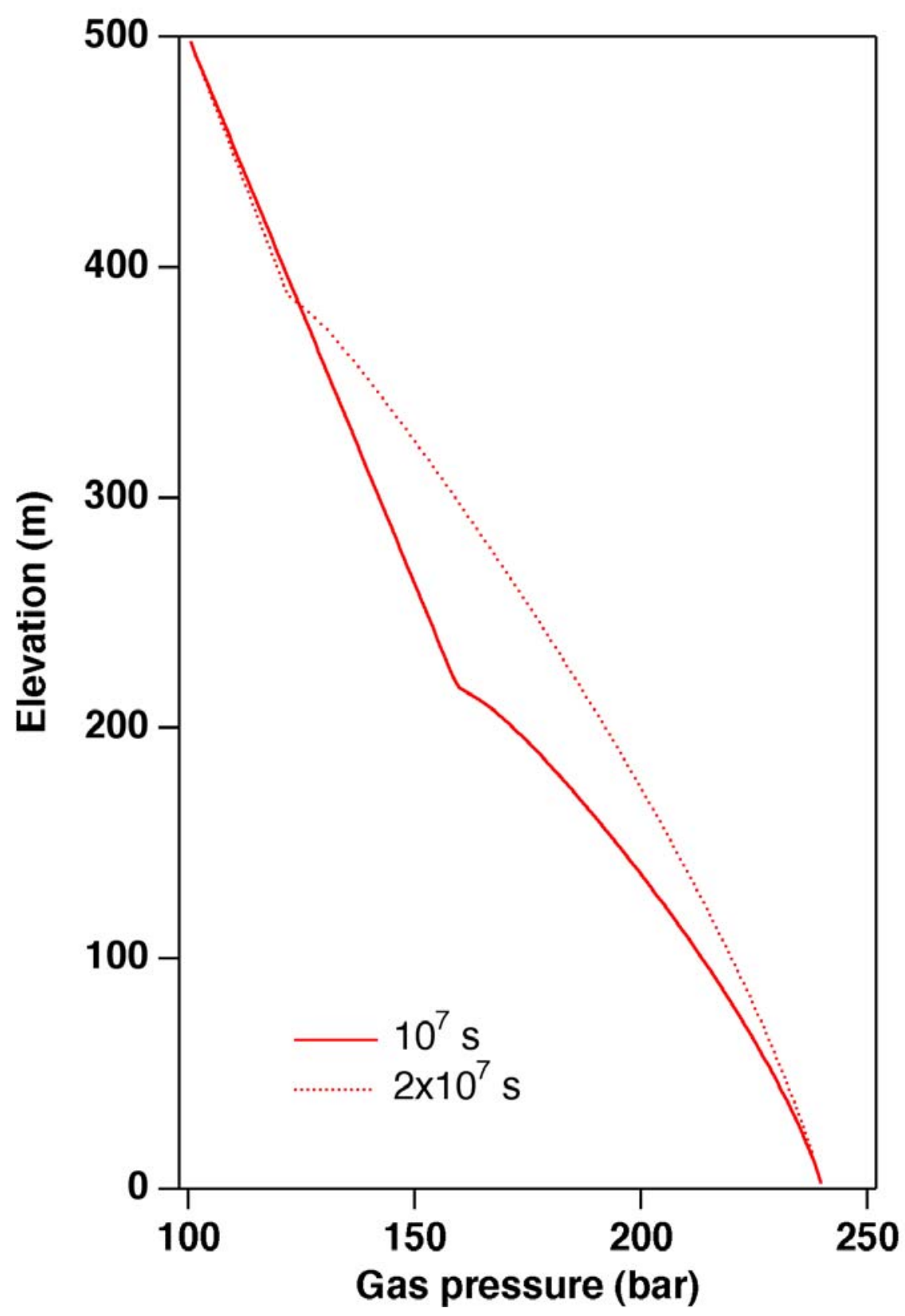

Figure 3.5 Pressure profiles at times of $10^{7}$ and $2 \times 10^{7}$ seconds.

$\mathrm{CO} 2$ gas entering from the block below is dissolved in the aqueous phase. The $\mathrm{CO} 2$ volume entering the block in effect disappears from the system, so that pressures decline. When the $\mathrm{CO} 2$ solubility limit is exceeded and a free gas phase forms this is accompanied by very rapid pressurization. Eventually gas saturation in the monitoring block increases to the point where gas phase becomes mobile, and is able to flow out to the next block above. This outflow is accompanied by rapid depressurization, which causes further increases in gas saturation due to expansion, 
enhancing gas mobility and accelerating outflow. From these considerations it is apparent that pressures are subject to severe fluctuations that are caused by space discretization effects. Simulated pressures have physical significance only in a time-averaged sense.

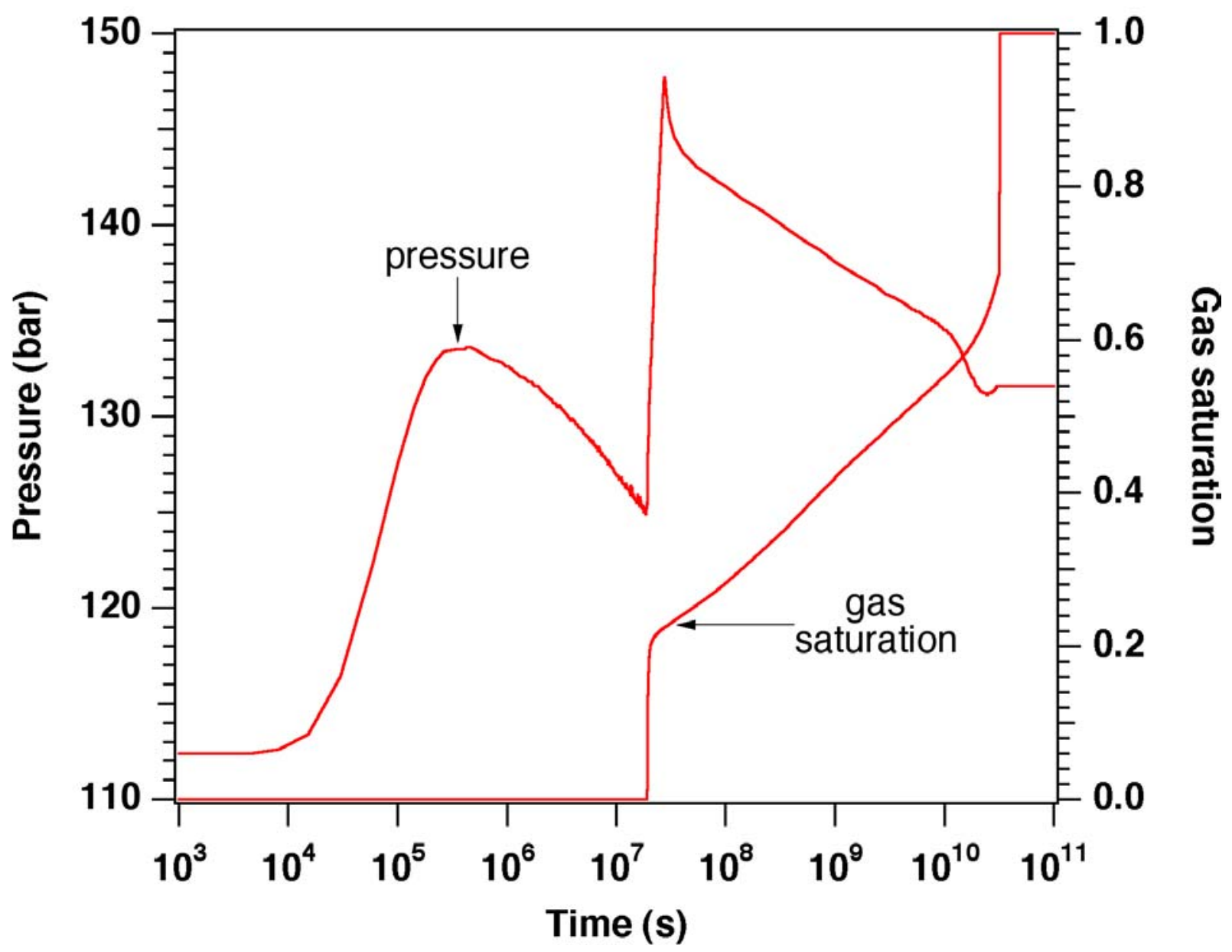

Figure 3.6 Transient evolution of pressures and gas saturations at a monitoring grid block, $372.5 \mathrm{~m}$ up the fault.

\subsection{Non-isothermal Variation}

To examine temperature effects associated with $\mathrm{CO} 2$ injection a non-isothermal version of the problem was simulated. This uses the same input file as shown in Fig. 3.2, except that in data block MULTI we specified to solve NEQ=4 equations, including the three mass balances for water, salt, and $\mathrm{CO} 2$, and a heat balance. (TOUGH2/ECO2 always solves a salt mass balance even if all salt concentrations are specified as zero.) For the thermal parameters we use generic values, including rock specific heat of $920 \mathrm{~J} / \mathrm{kg}{ }^{\circ} \mathrm{C}$, and formation thermal conductivity of $2.51 \mathrm{~W} / \mathrm{m}{ }^{\circ} \mathrm{C}$. $\mathrm{CO} 2$ is injected at conditions of $\mathrm{P}=240$ bar, $\mathrm{T}=45^{\circ} \mathrm{C}$; thermal conductivity of the injection grid 
block was set to zero, to avoid spurious heat conduction from that block into the fault system. Fig. 3.7 compares results for isothermal and non-isothermal calculations in which the Poynting correction for $\mathrm{CO} 2$ solubility was neglected. It is seen that gas saturation profiles at $10^{7}$ seconds for the non-isothermal run are virtually identical to those obtained for the isothermal version.

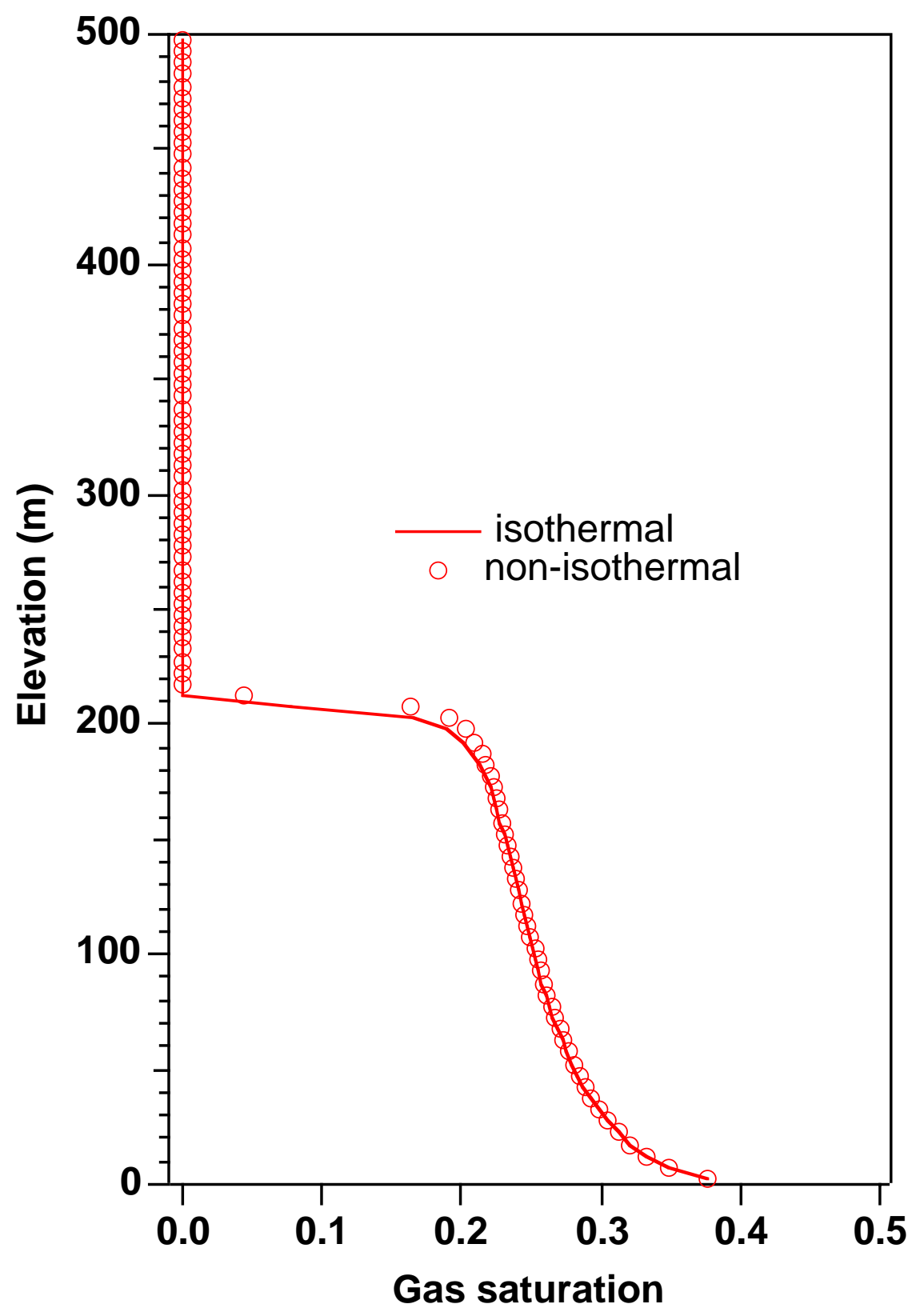

Figure 3.7 Gas saturation profiles at $10^{7}$ seconds for isothermal and non-isothermal conditions.

Fig. 3.8 shows simulated temperature profiles at a time of $10^{7}$ seconds, as well as for the steady single-phase gas flow conditions that are eventually reached at large simulation time. At $10^{7}$ 
seconds, temperatures in most of the two-phase zone are increased by approximately $3{ }^{\circ} \mathrm{C}$ relative to the initial $\mathrm{T}=45^{\circ} \mathrm{C}$, reflecting heat-of-dissolution effects as a portion of the $\mathrm{CO} 2$ is dissolved in the aqueous phase. At early times the temperature increase from heat-of-dissolution effects starts right at the injection boundary, but at later times some cooling occurs due to decompression of $\mathrm{CO} 2$ as it is flowing upwards. Fig. 3.9 presents the dependence of the specific enthalpy of $\mathrm{CO} 2$ on

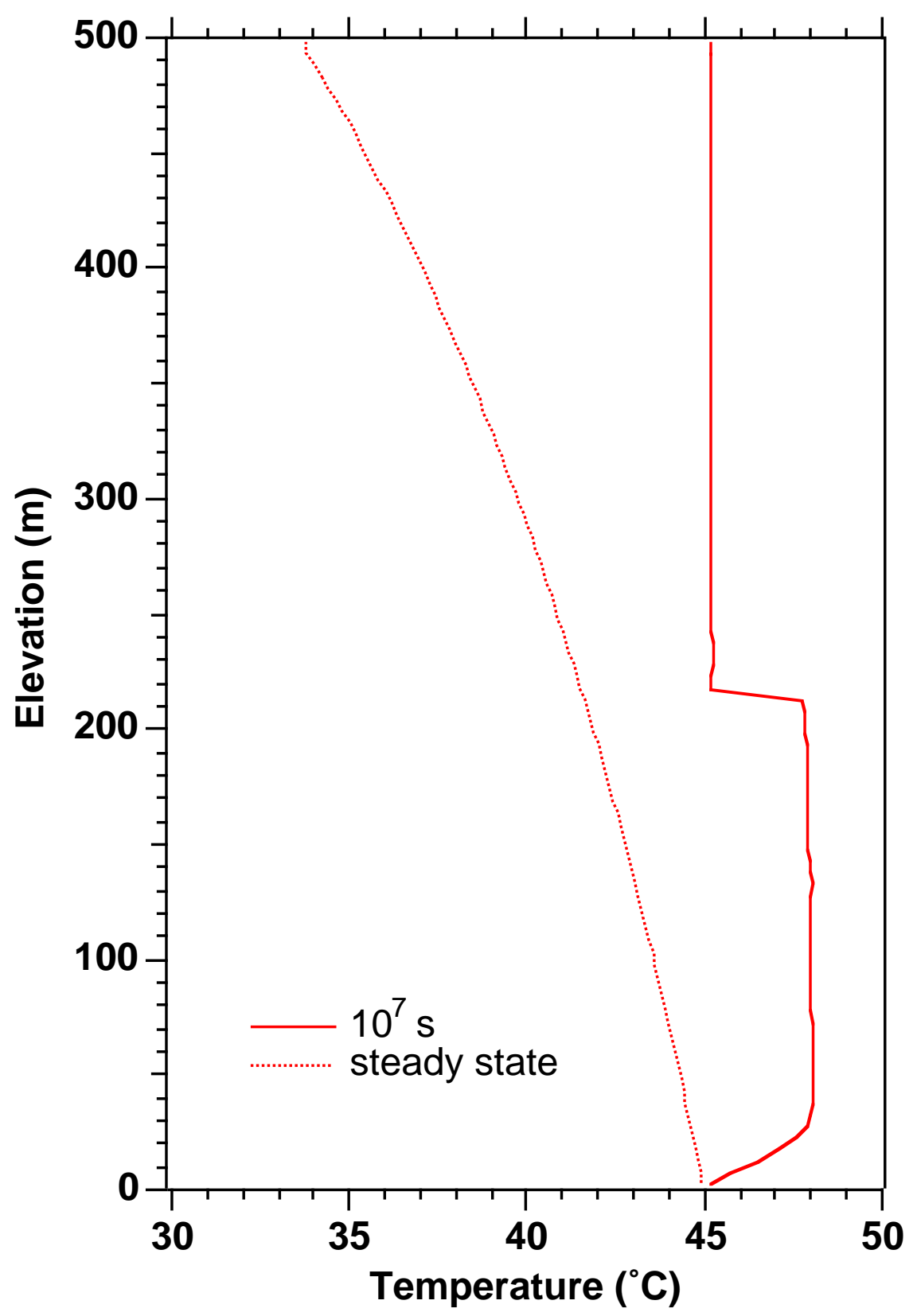

Figure 3.8 Temperature profiles for a non-isothermal version of the problem at $10^{7}$ seconds, and at the eventual steady state conditions. 
temperature and pressure, calculated from the correlations of Altunin (1975) used in our simulation. It is seen that adiabatic (isenthalpic) decompression of $\mathrm{CO} 2$ will result in a temperature decline, which explains the nature of the temperature profile obtained for the single-phase gas flow conditions at late time (Fig. 3.8).

Small temperature increases of approximately $0.2^{\circ} \mathrm{C}$ are seen at $10^{7}$ seconds ahead of the two-phase front. These are caused by compression effects in the aqueous phase.

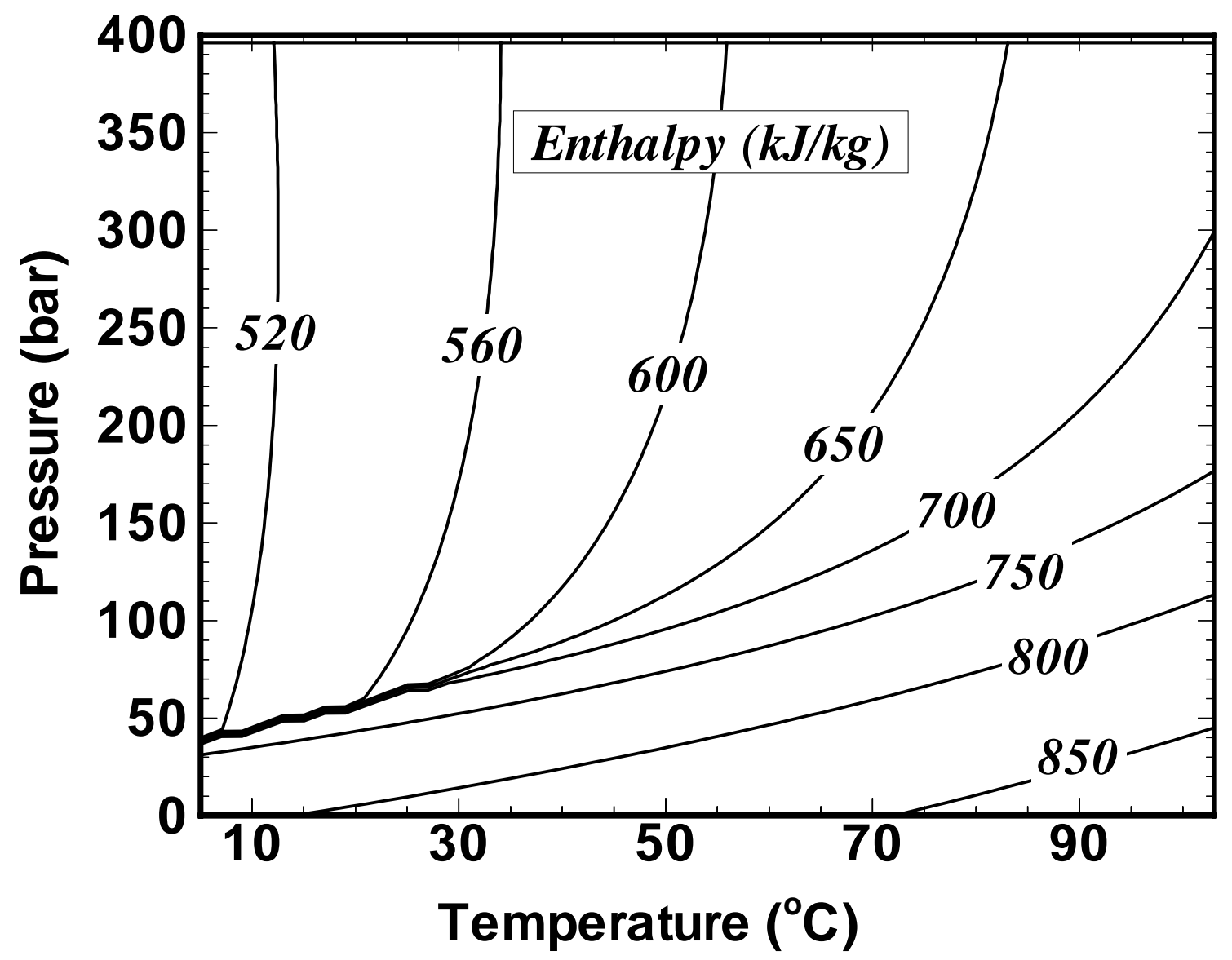

Figure 3.9 Enthalpy of pure $\mathrm{CO} 2$ as function of temperature and pressure, as calculated from the correlations of Altunin (1975). 


\section{Problem 7. $\mathrm{CO} 2$ Injection into a 2-D Layered Brine Formation}

The only industrial-scale $\mathrm{CO} 2$ disposal project currently in operation is at the Sleipner Vest field in the Norwegian sector of the North Sea, where approximately $10^{6}$ tonnes of $\mathrm{CO} 2$ per year are injected through a horizontal well into sands of the Utsira formation. Time-lapse seismic surveys have shown that $\mathrm{CO} 2$ migration at Sleipner is dominated by buoyancy effects and is strongly affected by shale interbeds of low permeability (Lindeberg et a., 2001). Test problem 7 was patterned after conditions at Sleipner and was designed to investigate $\mathrm{CO} 2$ migration in a heterogeneous sand-shale sequence. A 2-D vertical section was modeled (Fig. C.1, Appendix C), with problem specifications given in Appendix C.

This problem was simulated with the TOUGH2/ECO2 code, using fluid property descriptions as summarized in section 3, except that here we did not include a Poynting correction for $\mathrm{CO} 2$ solubility in the aqueous phase. Consequently, $\mathrm{CO} 2$ solubility in the aqueous phase is overestimated by as much as 1.5 percentage points which, however, has only a small impact on simulated system behavior. The problem was run in several segments to first obtain the initial and boundary conditions, and then inject $\mathrm{CO} 2$ according to specifications. All runs were performed in isothermal mode at a temperature of $37{ }^{\circ} \mathrm{C}$. Both a fresh water case and a case with 3.2 wt.- $\%$ salinity $(\mathrm{NaCl})$ were run.

The grid should be designed in such a way as to obtain "adequate" spatial resolution in regions where significant gradients occur, i.e., near the injection well, and near the shale layers (Fig. C.1). Also, simulation results are desired along prescribed horizontal and vertical profiles, and the gridding needs to accommodate these requirements. The grid is generated with the MESHMAKER facility of TOUGH2 as a horizontal (x-y) grid and is then rotated by 90 degrees around the $x$-axis to obtain a vertical section. Subroutine GXYZ was modified to automatically assign "sand" and "shale" domain identifiers to grid blocks at the appropriate elevations. Gridding in the $\mathrm{x}$-direction starts with $1 \mathrm{~m}$ increments at the well, and becomes coarser at increasing distance (Table 4.1). 28 grid blocks are used to get out to a distance of $6,000 \mathrm{~m}$, followed by a small grid increment of $10^{-3}$ $\mathrm{m}$ to serve as boundary blocks to maintain a hydrostatic pressure profile. Gridding in the $y-$ direction also uses a $1 \mathrm{~m}$ increment at the well, with coarser gridding below and above. The shale layers are represented as single grid layers of $3 \mathrm{~m}$ height, with $3 \mathrm{~m}$ gridding also in the sands above and below. The thickness of the grid is $1 \mathrm{~m}$. Overall the gridding is considered rather coarse, meeting minimum requirements for spatial resolution at the well and at the shale layers. 
Table 4.1 Grid increments (29 blocks in x from left to right; 34 blocks in y from bottom to top).

\begin{tabular}{|c|c|c|c|c|c|c|c|c|}
\hline \multicolumn{9}{|c|}{$\mathrm{XYZ}$} \\
\hline \multirow[t]{5}{*}{ NX } & 29 & & & & & & & \\
\hline & 1. & 1. & 2 . & 4. & 4. & 8. & 15. & 20 . \\
\hline & 30 . & 40 . & 50. & 50 . & 100. & 150. & 50. & 150. \\
\hline & 300 . & 50. & 475. & 500 . & 500. & 500. & 500 . & 500. \\
\hline & 500 . & 500. & 500. & 500. & $1 . e-3$ & & & \\
\hline \multirow[t]{6}{*}{ NY } & 34 & & & & & & & \\
\hline & 7. & 6. & 6. & 2.5 & 1. & 2.5 & 6. & 12. \\
\hline & 6. & 3. & 3. & 3. & 6. & 12. & 6. & 3. \\
\hline & 3. & 3. & 6. & 12. & 6. & 3. & 3. & 3. \\
\hline & 6. & 12. & 6. & 3. & 3. & 3. & 6. & 12. \\
\hline & 6. & 3 . & & & & & & \\
\hline NZ & 1 & 1.0 & & & & & & \\
\hline
\end{tabular}

\subsection{Thermophysical Properties}

Formation waters have a $\mathrm{CO} 2$ partial pressure of 0.5 bars, and are either fresh water or have a salinity of $3.2 \%$ by weight. Salinity specifications can be directly input into TOUGH2, as salt mass fraction is one of the primary variables. CO2 concentrations in TOUGH2/ECO2 are specified in terms of mass fractions as well, and brief trial-and-error runs were made to obtain the $\mathrm{CO} 2$ mass fractions that would correspond to a partial pressure of $0.5 \mathrm{bar}$, as stipulated in the problem specifications. The appropriate $\mathrm{CO} 2$ mass fractions were found to be $5.3009 \times 10^{-4}$ (fresh water), $4.5998 \times 10^{-4}$ (3.2 weight-\% brine), and $1.14795 \times 10^{-4}$ (saturated brine), reflecting the "salting out" effect of decreasing $\mathrm{CO} 2$ solubility with increasing salinity. $\mathrm{NaCl}$ mass fraction in saturated brine is 26.63 weight- $\%$.

Representative fluid properties as used in TOUGH2/ECO2 are given in Tables 4.2 and 4.3 for a temperature of $37^{\circ} \mathrm{C}$ at different salinities for a range of pressures. No allowance is presently made for dependence of brine density and viscosity on dissolved $\mathrm{CO} 2$.

Table 4.2. PVT properties at a temperature of $37{ }^{\circ} \mathrm{C}$ for different salinities (no CO2).

(a) density, $\mathrm{kg} / \mathrm{m}^{3}$

\begin{tabular}{|c|c|c|c|}
\hline $\begin{array}{c}\text { pressure } \\
\text { (bars) }\end{array}$ & fresh water & $\begin{array}{c}3.2 \text { wt.-\% } \\
\text { brine }\end{array}$ & $\begin{array}{c}\text { saturated } \\
\text { brine }\end{array}$ \\
\hline \hline 90 & 996.68 & 1017.83 & 1196.26 \\
\hline 100 & 997.05 & 1018.19 & 1196.71 \\
\hline 120 & 997.79 & 1018.92 & 1197.61 \\
\hline 140 & 998.54 & 1019.65 & 1198.51 \\
\hline 160 & 999.28 & 1020.38 & 1199.41 \\
\hline 180 & 1000.02 & 1021.11 & 1200.31 \\
\hline
\end{tabular}


(b) viscosity, $10^{-4} \mathrm{~Pa}-\mathrm{s}$

\begin{tabular}{|c|c|c|c|}
\hline $\begin{array}{c}\text { pressure } \\
\text { (bars) }\end{array}$ & fresh water & $\begin{array}{c}3.2 \text { wt.- } \% \\
\text { brine }\end{array}$ & $\begin{array}{c}\text { saturated } \\
\text { brine }\end{array}$ \\
\hline \hline 90 & 6.9208 & 7.3201 & 14.055 \\
\hline 100 & 6.9214 & 7.3207 & 14.056 \\
\hline 120 & 6.9225 & 7.3219 & 14.058 \\
\hline 140 & 6.9237 & 7.3232 & 14.061 \\
\hline 160 & 6.9251 & 7.3246 & 14.063 \\
\hline 180 & 6.9265 & 7.3261 & 14.066 \\
\hline
\end{tabular}

Table 4.3. PVT properties at a temperature of $37^{\circ} \mathrm{C}$ for two-phase fluid mixtures of water, $\mathrm{CO} 2$, and $\mathrm{NaCl}$.

(a) fresh water (no salinity)

\begin{tabular}{|c|c|c|c|c|c|c|}
\hline $\begin{array}{c}\text { pressure } \\
(\text { bars })\end{array}$ & $\begin{array}{c}\text { aq. density } \\
\left(\mathrm{kg} / \mathrm{m}^{3}\right)\end{array}$ & $\begin{array}{c}\text { gas density } \\
\left(\mathrm{kg} / \mathrm{m}^{3}\right)\end{array}$ & $\begin{array}{c}\text { aq. viscosity } \\
\left(10^{-4} \mathrm{~Pa} \mathrm{~s}\right)\end{array}$ & $\begin{array}{c}\text { gas } \\
\text { viscosity } \\
\left(10^{-5} \mathrm{~Pa} \mathrm{~s}\right)\end{array}$ & $\begin{array}{c}\text { CO2 mass } \\
\text { fraction } \\
\left(\mathrm{aq} . ; 10^{-2}\right)\end{array}$ & $\begin{array}{c}\mathrm{H} 2 \mathrm{O} \text { mass } \\
\text { fraction } \\
\left(\text { gas; } 10^{-5}\right)\end{array}$ \\
\hline \hline 90 & 996.68 & 606.61 & 6.9208 & 4.5731 & 5.8600 & 7.2422 \\
\hline 100 & 997.05 & 684.06 & 6.9214 & 5.4613 & 6.2100 & 6.4221 \\
\hline 120 & 997.79 & 749.33 & 6.9225 & 6.3711 & 6.8100 & 5.8627 \\
\hline 140 & 998.54 & 787.46 & 6.9237 & 6.9830 & 7.3000 & 5.5789 \\
\hline 160 & 999.28 & 815.36 & 6.9251 & 7.4752 & 7.6900 & 5.3880 \\
\hline 180 & 1000.02 & 837.59 & 6.9265 & 7.8982 & 8.0300 & 5.2449 \\
\hline
\end{tabular}

(b) 3.2 weight $\%$ salinity

\begin{tabular}{|c|c|c|c|c|c|c|}
\hline $\begin{array}{c}\text { pressure } \\
\text { (bars) }\end{array}$ & $\begin{array}{l}\text { aq. density } \\
\left(\mathrm{kg} / \mathrm{m}^{3}\right)\end{array}$ & $\begin{array}{l}\text { gas density } \\
\left(\mathrm{kg} / \mathrm{m}^{3}\right)\end{array}$ & $\begin{array}{l}\text { aq. viscosity } \\
\left(10^{-4} \mathrm{~Pa} \mathrm{~s}\right)\end{array}$ & $\begin{array}{c}\text { gas } \\
\text { viscosity } \\
\left(10^{-5} \mathrm{~Pa} \mathrm{~s}\right) \\
\end{array}$ & $\begin{array}{c}\text { CO2 mass } \\
\text { fraction } \\
\left(\mathrm{aq} . ; 10^{-2}\right)\end{array}$ & $\begin{array}{c}\text { H2O mass } \\
\text { fraction } \\
\text { (gas; } 10^{-5} \text { ) }\end{array}$ \\
\hline 90 & 1017.83 & 0.62 & 7.3201 & 4.5733 & 5.1071 & 7.0995 \\
\hline 100 & 10 & 68 & 7.3207 & 5.4614 & 5.4147 & 6.2957 \\
\hline 120 & 1018.92 & 749.33 & 7.3219 & 6.3 & 5.9388 & 5.7474 \\
\hline 140 & 1019.65 & 787.46 & 7.3232 & 6.9830 & 6.3642 & 5.4691 \\
\hline 160 & 1020.38 & 815.36 & 7.3246 & 7.4753 & 6.7134 & 5.2820 \\
\hline 180 & 1021.11 & 837.6 & 7.3261 & 7.8982 & 7.0043 & 5.1418 \\
\hline
\end{tabular}

\subsection{Gravity Equilibration}

Initial conditions are generated in stages. A first simulation run involves just the column of boundary grid blocks beyond $\mathrm{x}=6,000 \mathrm{~m}$. Thermodynamic properties are specified as $\mathrm{P}=110$ bars, $\mathrm{T}=37^{\circ} \mathrm{C}$, salinity $\mathrm{X}_{\mathrm{s}}=0.032, \mathrm{CO} 2$ mass fraction $\mathrm{X}_{\mathrm{CO} 2}=4.5998 \times 10^{-4}$. Pressure is held constant at $\mathrm{P}=110$ bar at the elevation of the injection node $(22 \mathrm{~m})$ and the system is run to gravity equilibrium. To facilitate reaching an accurate equilibrium state, the shale layers are given the same 
absolute permeability as the sand layers for this simulation. Gravity equilibrium using a tight convergence tolerance of $10^{-8}$ is attained in seven time steps for both fresh water and 3.2 wt.- $\%$ salinity cases, corresponding to a simulation time of $3.25 \times 10^{9} \mathrm{~s}$. Maximum pore velocities in the equilibrium state are below 10-17 m/s. The pressure profiles at gravity equilibrium are given in Fig. 4.1, showing only small differences between the fresh water and $3.2 \%$ salinity cases. A second run with the full two-dimensional grid is then performed, using the same initialization as for the 1-D gravity equilibration just described, and maintaining the 1-D gravity equilibrium as boundary conditions at the right hand side. For this calculation we again specify the same absolute permeability for shale as for sand. Gravity equilibration in the 2-D grid takes 14 time steps for the

fresh water case, and 12 time steps for $3.2 \mathrm{wt} .-\%$ salinity, for simulation times of $1.14 \times 10^{10} \mathrm{~s}$ and $2.93 \times 10^{9} \mathrm{~s}$, respectively.

\subsection{CO2 Injection}

The TOUGH2 input file for $\mathrm{CO} 2$ injection into brine with $3.2 \mathrm{wt} .-\%$ salinity at a constant prescribed rate of $0.1585 \mathrm{~kg} / \mathrm{s}$ is shown in Fig. 4.2. This input file specifies a total simulation time of $2.592 \times 10^{6} \mathrm{~s}$ (30 days), because $\mathrm{CO} 2$ mass balances are desired at this time. Continuation runs are then performed to reach times of one year $\left(3.15576 \times 10^{7} \mathrm{~s}\right)$ and two years $\left(6.31152 \times 10^{7} \mathrm{~s}\right)$. The runs with and without salinity proceed in very similar fashion, and both require 587 time steps to reach the final simulation time of two years. Time steps gradually increase during the course of the simulation, as can be seen from the negative curvature of the time step vs. time curve in Fig. 4.3. Gas saturation at the wellblock quickly reaches a quasi-steady value of approximately $53 \%$ (Fig. 4.3). Fluid salinity at the wellblock keeps increasing over time as water is slowly being removed by evaporation into the $\mathrm{CO} 2$ stream (Fig. 4.4). CO2 mass fraction in the aqueous phase slowly decreases, as $\mathrm{CO} 2$ solubility declines with increasing salinity.

Figs. 4.5 and 4.6 show contour plots of gas saturation and $\mathrm{CO} 2$ mass fraction dissolved in the aqueous phase after two years of $\mathrm{CO} 2$ injection. Highest gas saturations of approximately $60 \%$ occur beneath the shale layers at elevations of 52,85, and $118 \mathrm{~m}$. Gas is just beginning to reach the top shale layer at an elevation of $151 \mathrm{~m}$. CO2 mass fraction dissolved in the aqueous phase after two years is in the range of 5 - $6 \%$ throughout most of the two-phase zone, with smaller but significant aqueous $\mathrm{CO} 2$ concentrations occurring beyond the two-phase region.

Gas saturations along vertical profiles at different distances from the left boundary after two years are shown in Fig. 4.7. Buoyancy effects are evident from the large gas saturations beneath the shales, and from the increase in elevation of the lower boundary of the two-phase zone with increasing distance from the injection well. In the time period from one to two years, gas saturations 
at $200 \mathrm{~m}$ distance increase most strongly beneath and above the third shale layer at $118 \mathrm{~m}$ elevation (Fig. 4.8). Gas saturation profiles for the simulations with and without salinity are almost identical (Fig. 4.9), the most significant difference being the slightly larger gas saturation beneath the top shale (elevation $151 \mathrm{~m}$ ) for the saline case. This can be understood from the reduced CO2 solubility under saline conditions, which places a slightly larger fraction of total CO2 into the gas phase, see Table 4.4.

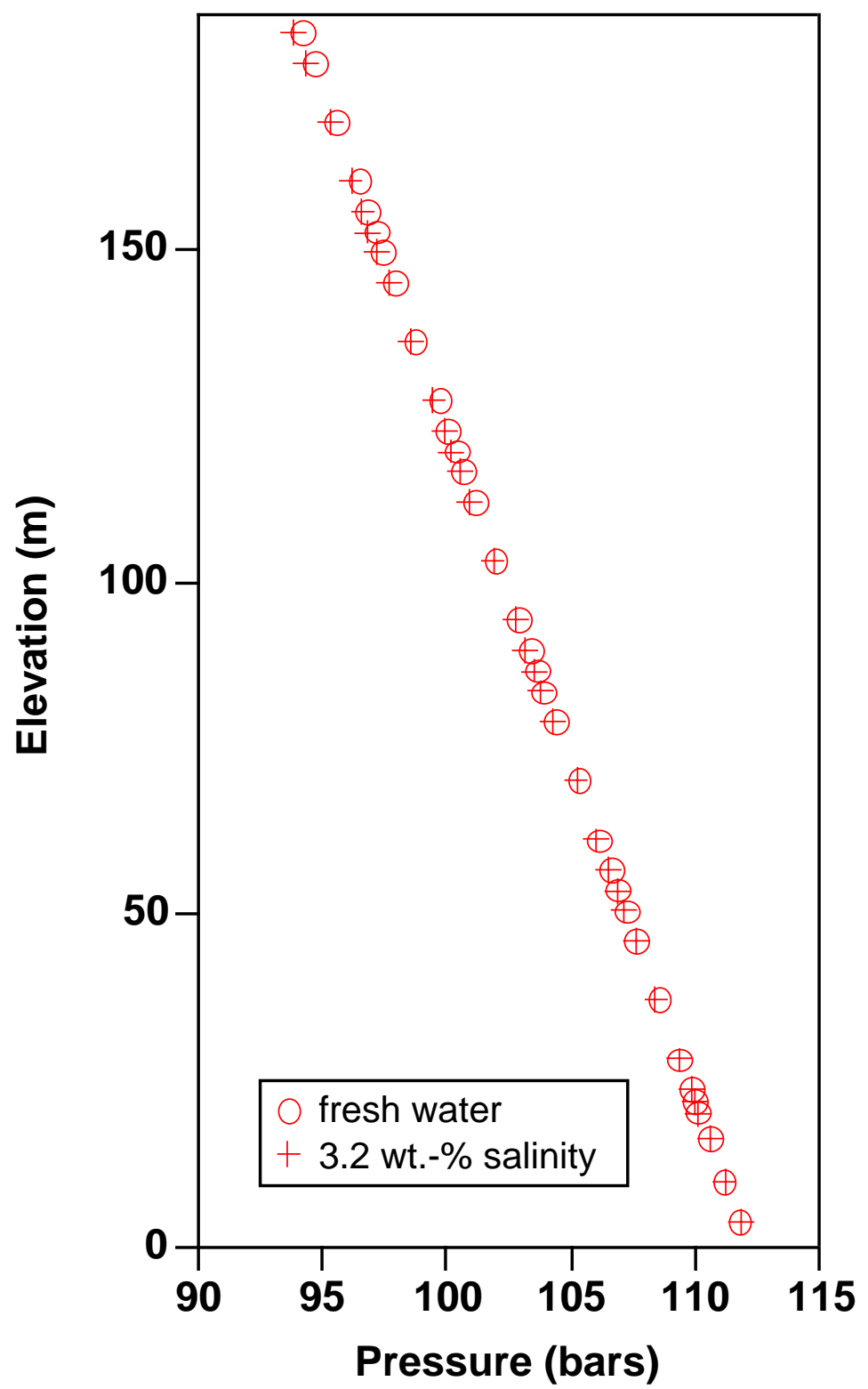

Figure 4.1 Hydrostatic pressure profile prior to $\mathrm{CO} 2$ injection. 


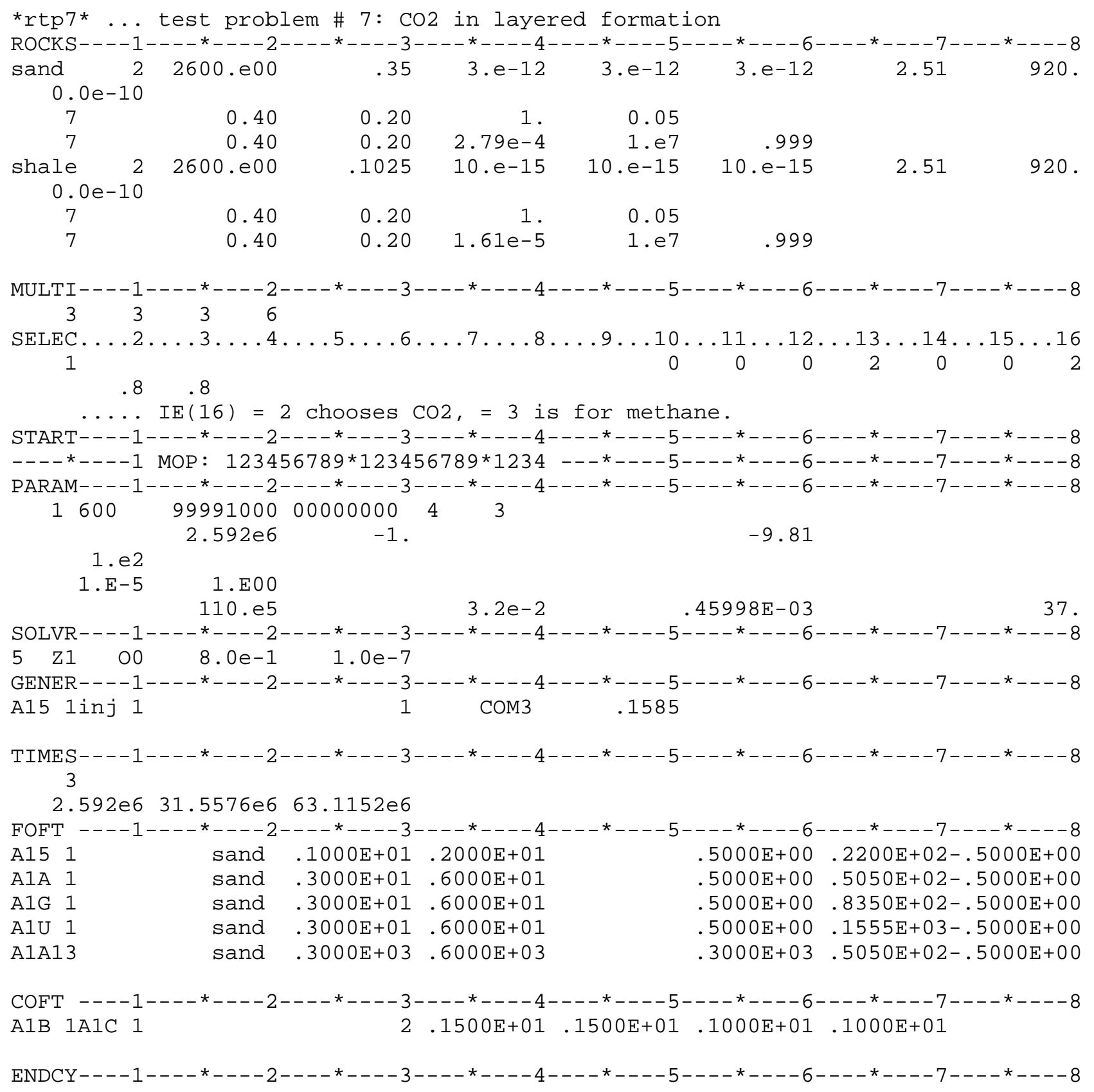

Figure 4.2 TOUGH2 input file for $\mathrm{CO} 2$ injection into layered brine formation. 


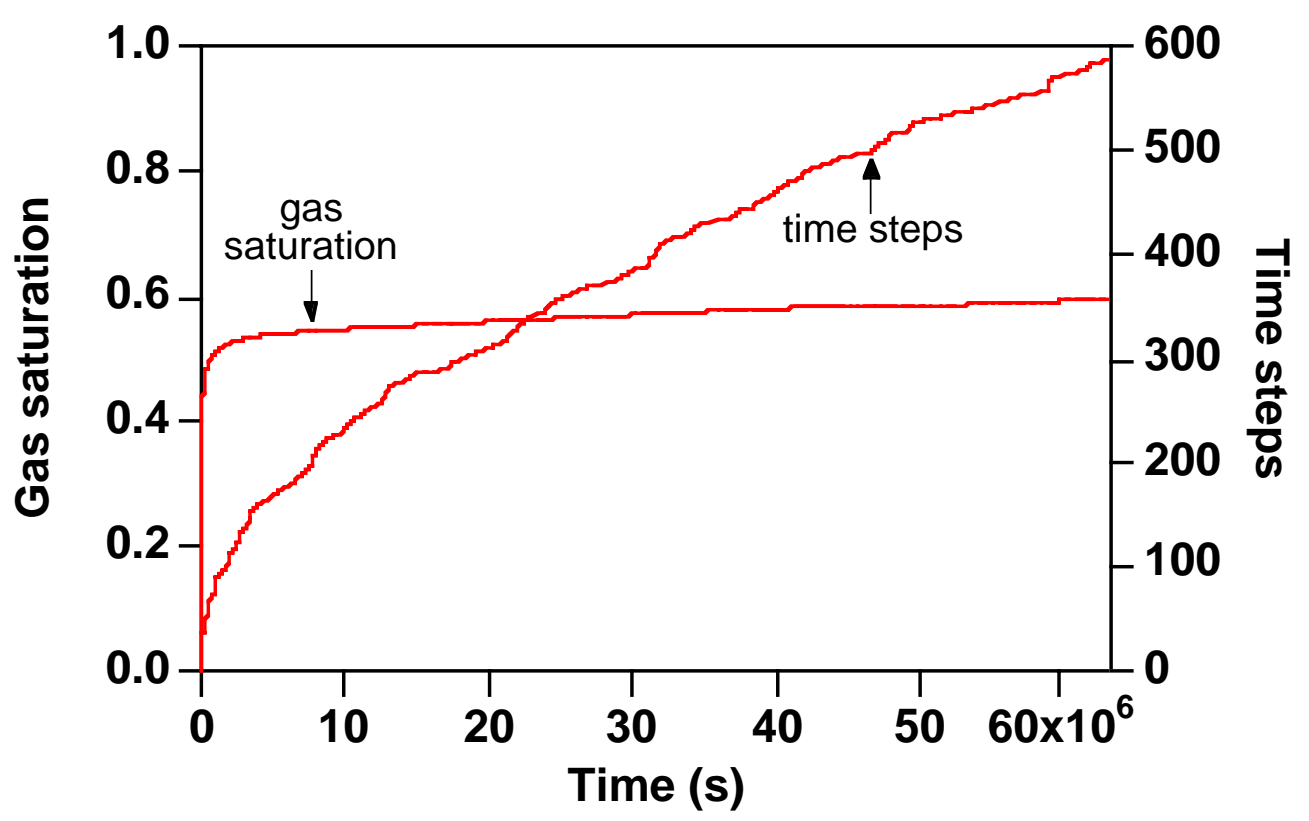

Figure 4.3 Time stepping and gas saturation vs. time at the wellblock for the case with 3.2 wt.- $\%$ salinity.

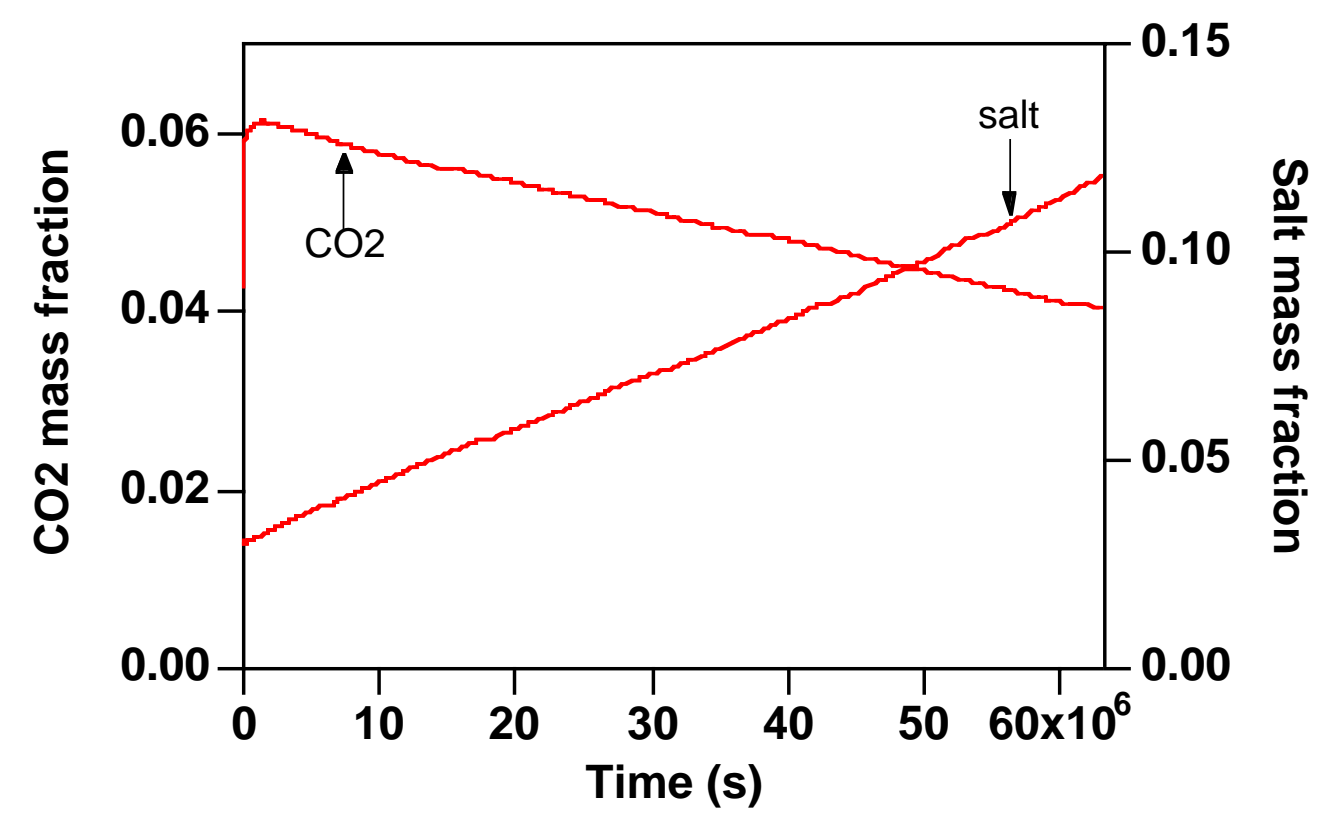

Figure 4.4 CO2 and salt mass fractions in the aqueous phase at the wellblock for the case with 3.2 wt.-\% salinity. 


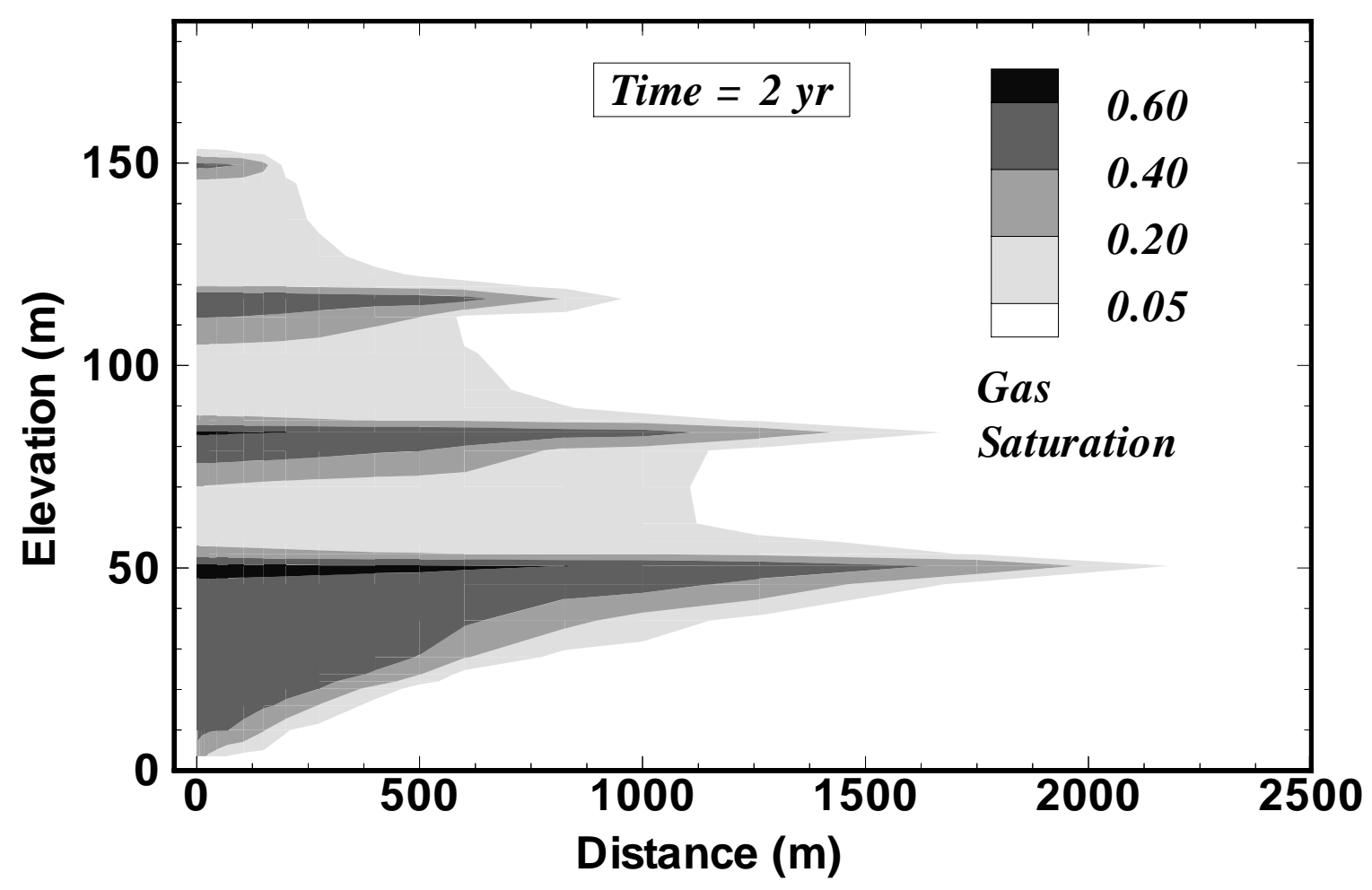

Figure 4.5 Gas saturation after 2 years of $\mathrm{CO} 2$ injection for the case with 3.2 wt.- $\%$ salinity.

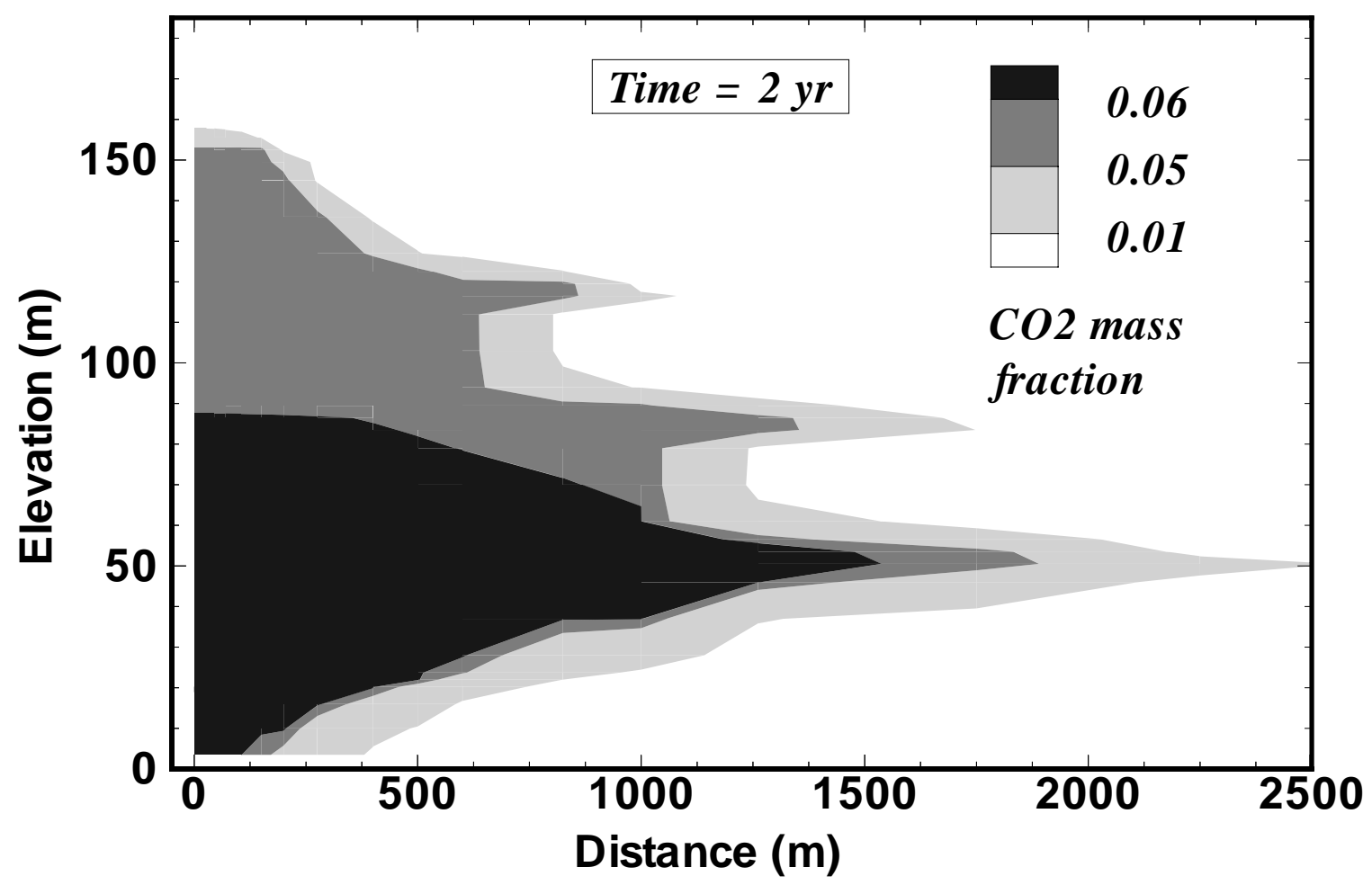

Figure 4.6 $\mathrm{CO} 2$ mass fraction dissolved in the aqueous phase after 2 years of $\mathrm{CO} 2$ injection for the case with 3.2 wt.- $\%$ salinity. 


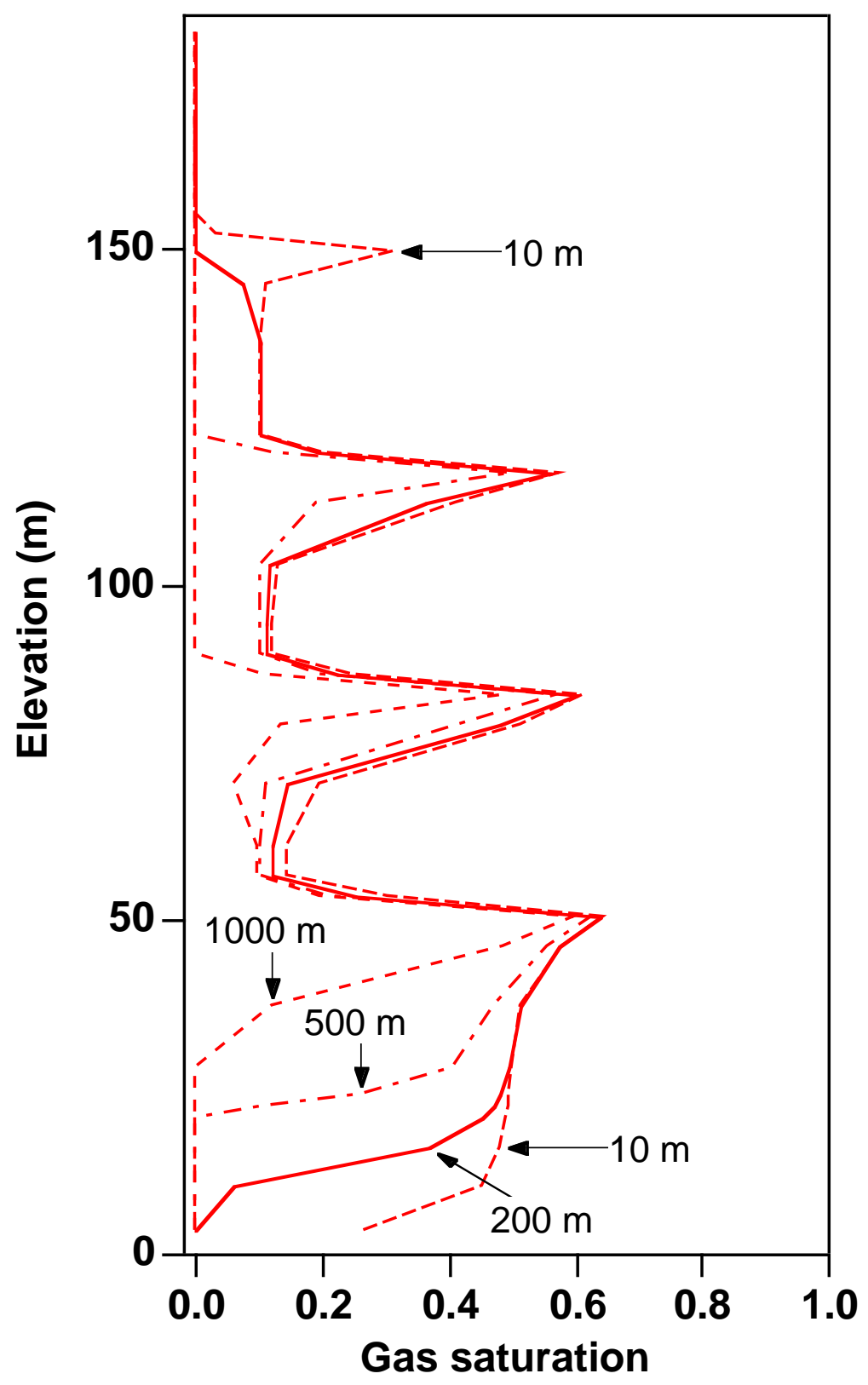

Figure 4.7 Vertical profiles of gas saturation after two years at different distances from the left boundary for the case with $3.2 \mathrm{wt} .-\%$ salinity. 


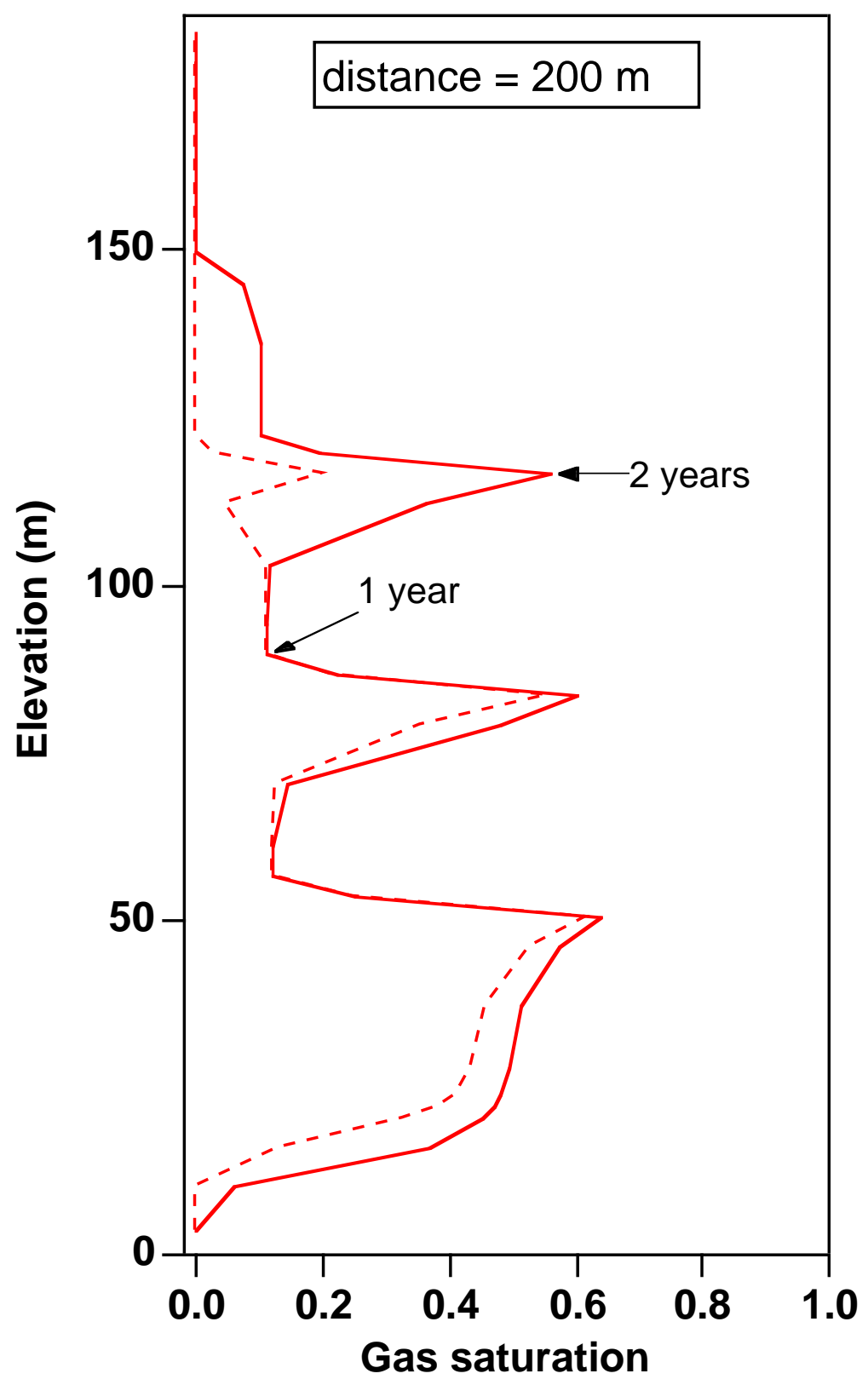

Figure 4.8 Vertical profiles of gas saturation at $200 \mathrm{~m}$ distance from the left boundary for the case with 3.2 wt.-\% salinity. 


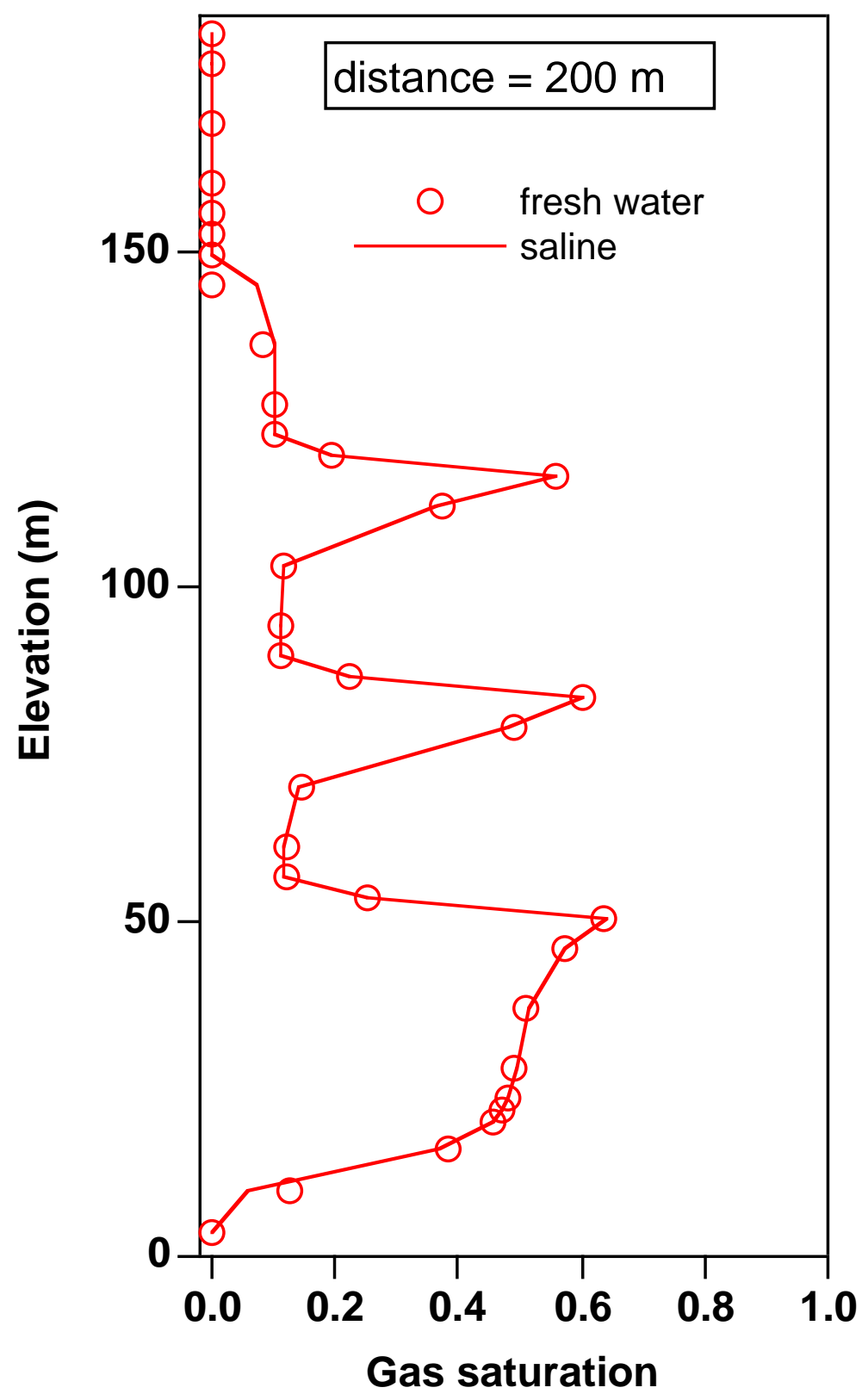

Figure 4.9 Vertical profiles of gas saturation at $200 \mathrm{~m}$ distance from the left boundary after 2 years. 
Table 4.4 CO2 mass balances (in units of $10^{6} \mathrm{~kg}$ ) for injection into fresh water and saline systems.

\begin{tabular}{|c|c|c|c|c|c|c|c|c|}
\hline & \multicolumn{2}{|c|}{$t=0$} & \multicolumn{2}{|c|}{30 days } & \multicolumn{2}{|c|}{1 year } & \multicolumn{2}{|c|}{2 years } \\
\hline & fresh & saline & fresh & saline & fresh & saline & fresh & saline \\
\hline total $\mathrm{CO} 2$ & 0.2042 & 0.1810 & 0.6149 & 0.5916 & 5.203 & 5.180 & 0.20 & 10.18 \\
\hline CO2 injected & \multicolumn{2}{|c|}{0.0000} & \multicolumn{2}{|c|}{0.4108} & \multicolumn{2}{|c|}{5.002} & \multicolumn{2}{|c|}{10.00} \\
\hline CO2 (aq.) & 0.2042 & 0.1810 & 0.3184 & 0.2876 & 1.360 & 1.274 & 2.525 & 2.330 \\
\hline CO2 (gas) & 0.0000 & 0.0000 & 0.2965 & 0.3040 & 3.843 & 3.906 & 7.677 & 7.849 \\
\hline $\begin{array}{l}\text { fraction of } \mathrm{CO} 2 \\
\text { in aq. phase }\end{array}$ & 1.000 & 0 & 0.5178 & 0.4861 & 4 & 60 & 2475 & 289 \\
\hline
\end{tabular}

\section{Concluding Remarks}

This study has considered three numerical simulation problems for displacement of water by $\mathrm{CO} 2$ that were posed as part of an intercomparison study of numerical simulation codes. The problems considered are prototypical for, respectively, $\mathrm{CO} 2$ injection from a vertical well (Problem 3), leakage of $\mathrm{CO} 2$ from a storage reservoir (Problem 4), and disposal of $\mathrm{CO} 2$ into a layered heterogeneous formation from a horizontal well (Problem 7). LBNL's general purpose TOUGH2 reservoir simulator was used in conjunction with special fluid property modules developed for multiphase mixtures of water, $\mathrm{CO} 2$ and salt $(\mathrm{NaCl})$ for the temperature and pressure conditions of interest in geologic disposal of $\mathrm{CO} 2$. Issues addressed in the simulations include thermophysical properties of fluids, phase partitioning between aqueous and CO2-rich (gas-like) phases, immiscible displacement of water by $\mathrm{CO} 2$, interplay of viscous, gravitational, and capillary forces, and role of heterogeneities. Detailed results for simulated systems behavior are given along with data for fluid properties, to provide benchmarks against which other simulation codes may be tested.

\section{Acknowledgement}

We thank Christine Doughty and André Unger for a review of the manuscript. The specifications for Problem 7 were developed by Carl Steefel. This work was supported by the U.S. Department of Energy through the Office of Basic Energy Sciences and through the National Energy Technology Laboratory (NETL) under Contract No. DE-AC03-76SF00098. 


\section{References}

Altunin, V.V. Thermophysical Properties of Carbon Dioxide, Publishing House of Standards, 551 pp., Moscow, 1975 (in Russian).

Battistelli, A., C. Calore and K. Pruess. The Simulator TOUGH2/EWASG for Modeling Geothermal Reservoirs with Brines and Non-Condensible Gas, Geothermics, Vol. 26, No. 4, pp. 437 - 464, 1997.

Chou I.M. Phase Relations in the System NaCl-KCl-H ${ }_{2} \mathrm{O}$. III: Solubilities of Halites in VaporSaturated Liquids above $445^{\circ} \mathrm{C}$ and Redetermination of Phase Equilibrium Properties of the System NaCl-H 2 O. Geochim Cosmochim Acta, Vol. 51, pp. 1965 - 1975, 1987.

Doughty, C. and K. Pruess. A Similarity Solution for Two-Phase Water, Air and Heat Flow Near a Linear Heat Source in a Porous Medium, J. of Geophys. Res., Vol. 97 (B2), pp. 1821 - 1838, 1992.

García, J. Density of Aqueous Solutions of CO2, Lawrence Berkeley National Laboratory Report LBNL-49023, Berkeley, CA, 2001.

Haas, J.L. Jr. Physical Properties of the Coexisting Phases and Thermochemical Properties of the $\mathrm{H} 2 \mathrm{O}$ Component in Boiling $\mathrm{NaCl}$ solutions, USGS Bulletin 1421-A, Washington, DC, 73 pp., 1976.

Hitchon, B. (ed.). Aquifer Disposal of Carbon Dioxide, Geoscience Publishing, Ltd., Sherwood Park, Alberta, Canada, 1996.

International Formulation Committee. A Formulation of the Thermodynamic Properties of Ordinary Water Substance, IFC Secretariat, Düsseldorf, Germany, 1967.

Lindeberg, E., P. Zweigel, P. Bergmo, A. Ghaderi, and A. Lothe. Prediction of CO2 Distribution Pattern Improved by Geologic and Reservoir Simulation and Verified by Time Lapse Seismic, in: D. Williams et al. (eds.), Proceedings, Fifth International Conference on Greenhouse Gas Control Technologies, pp. 372 - 377, CSIRO Publ., Collingwood, VIC, Australia, 2001.

Oldenburg, C.M., D. H.-S. Law, Y. Le Gallo, and S.P. White. Mixing of CO2 and CH4 in Gas Reservoirs: Code Comparison Studies, paper F1-1, presented at Sixth International Conference on Greenhouse Gas Technologies (GHGT-6), Kyoto, Japan, October 1-4, 2002.

O’Sullivan, M.J. A Similarity Method for Geothermal Well Test Analysis, Water Resour. Res., Vol. 17, No. 2, pp. $390-398,1981$.

Pape, H., C. Clauser and J. Iffland. Permeability Prediction Based on Fractal Pore-Space Geometry, Geophysics, Vol. 64, No. 5, pp. 1447 - 1460, 1999.

Phillips, S.L., A. Igbene, J.A. Fair, H. Ozbek and M. Tavana. A Technical Databook for Geothermal Energy Utilization, Lawrence Berkeley National Laboratory Report LBL-12810, Berkeley, CA, 46 pp., 1981.

Prausnitz, J. M., R. N. Lichtenthaler, and E. G. de Azevedo. Molecular Thermodynamics of FluidPhase Equilibria, Prentice-Hall Inc., Englewood Cliffs, N. J., 1986.

Pruess, K., C. Oldenburg and G. Moridis. TOUGH2 User's Guide, Version 2.0, Lawrence Berkeley National Laboratory Report LBNL-43134, Berkeley, CA, November 1999. 
Pruess, K., C.F. Tsang, D. H.-S. Law and C.M. Oldenburg. Intercomparison of Simulation Models for CO2 Disposal in Underground Storage Reservoirs, Lawrence Berkeley National Laboratory Report LBNL-47353, October 2000.

Pruess, K. and J. García. Multiphase Flow Dynamics During CO2 Injection into Saline Aquifers, Environmental Geology, Vol. 42, pp. 282 - 295, 2002.

Pruess, K., A. Bielinski, J. Ennis-King, R. Fabriol, Y. Le Gallo, J. García, K. Jessen, T. Kovscek, D. H.-S. Law, P. Lichtner, C. Oldenburg, R. Pawar, J. Rutqvist, C. Steefel, B. Travis, C.F. Tsang, S. White, T. Xu. Code Intercomparison Builds Confidence in Numerical Models for Geologic Disposal of CO2, paper F1-4, presented at Sixth International Conference on Greenhouse Gas Technologies (GHGT-6), Kyoto, Japan, October 1-4, 2002a. (LBNL51200)

Pruess, K., J. García, T. Kovscek, C. Oldenburg, J. Rutqvist, C. Steefel and T. Xu. Intercomparison of Numerical Simulation Codes for Geologic Disposal of CO2, Lawrence Berkeley National Laboratory Report LBNL-51813, Berkeley, CA 94720, December 2002 b.

Spycher, N., K. Pruess and J. Ennis-King. $\mathrm{CO}_{2}-\mathrm{H}_{2} \mathrm{O}$ Mixtures in the Geological Sequestration of $\mathrm{CO}_{2}$. I. Assessment and Calculation of Mutual Solubilities from 12 to $100{ }^{\circ} \mathrm{C}$ and up to 600 bar, submitted to Geochim. Cosmochim. Acta, July 2002. (LBNL-50991)

Spycher, N.F. and M.H. Reed. Fugacity Coefficients of H2, CO2, CH4, H2O and of H2O-CO2CH4 Mixtures: A Virial Equation Treatment for Moderate Pressures and Temperatures Applicable to Calculations of Hydrothermal Boiling, Geochim. Cosmochim. Acta, Vol. 52, pp. 739 - 749, 1988.

van Genuchten, M.Th. A Closed-Form Equation for Predicting the Hydraulic Conductivity of Unsaturated Soils, Soil Sci. Soc. Am. J., Vol. 44, pp. 892 - 898, 1980.

Verma, A. and K. Pruess. Thermohydrologic Conditions and Silica Redistribution Near HighLevel Nuclear Wastes Emplaced in Saturated Geological Formations, Journal of Geophysical Res., 93 (B2), pp. 1159-1173, 1988. 


\section{APPendix A. Test Problem 3: Radial Flow from a CO2 Injection Well\&}

\section{INTRODUCTION AND GENERAL DESCRIPTION}

This problem addresses two-phase flow of $\mathrm{CO} 2$ and water for simplified flow geometry and medium properties. The aquifer into which injection is made is assumed infinite-acting, homogenoeus, and isotropic. Gravity and inertial effects are neglected, injection is made at a constant mass rate, and flow is assumed 1-D radial (line source). Under the conditions stated the problem has a similarity solution where dependence on radial distance $\mathrm{R}$ and time t occurs only through the similarity variable $\xi=\mathrm{R}^{2} / \mathrm{t}$ (O'Sullivan 1981; Doughty and Pruess 1992).

\section{LIST OF PROCESSES BEING STUDIED}

Two-phase flow of $\mathrm{CO} 2$ and water subject to relative permeability and capillary effects. Change of fluid density, viscosity, and $\mathrm{CO} 2$ solubility with pressure and salinity. Formation dry-out with precipitation of salt.

\section{DEFINITION OF THE PROBLEM AND INPUT DATA}

Problem parameters are summarized in Tables A.1 and A.2.

\section{PROBLEM VARIATIONS}

Neglect salinity of the aqueous phase. Include non-isothermal effects. Include permeability changes due to precipitation. Inject gas that is $50 \% \mathrm{CO} 2,50 \% \mathrm{~N} 2$.

\section{DEFINITION OF RESULTS TO BE CALCULATED}

Data on $\mathrm{CO} 2$ and brine density and viscosity, and $\mathrm{CO} 2$ solubility, for the range of thermodynamic conditions encountered in the problem. Gas saturation, dissolved $\mathrm{CO} 2$ mass fraction, fraction of void space containing precipitated salt, and fluid pressure as functions of the similarity variable $\xi=$ $\mathrm{R}^{2 / t}$. (Use both profiles at constant time and time-series data at a specific location for plotting.)

\section{COMPARISON CRITERIA}

Results should match within $+/-5 \%$.

\section{REFERENCES}

Corey, A.T. The Interrelation Between Gas and Oil Relative Permeabilities, Producers Monthly, pp. 38 - 41, November 1954.

\footnotetext{
\& proposed by Karsten Pruess; e-mail: K_Pruess@ @lbl.gov
} 
Doughty, C. and K. Pruess. A Similarity Solution for Two-Phase Water, Air and Heat Flow Near a Linear Heat Source in a Porous Medium, J. of Geophys. Res., 97 (B2), 1821-1838, 1992.

O’Sullivan, M.J. A Similarity Method for Geothermal Well Test Analysis, Water Resour. Res., Vol. 17, No. 2, pp. $390-398,1981$.

van Genuchten, M.Th. A Closed-Form Equation for Predicting the Hydraulic Conductivity of Unsaturated Soils, Soil Sci. Soc. Am. J., Vol. 44, pp. 892 - 898, 1980.

Table A.1 Hydrogeologic parameters.

\begin{tabular}{|c|c|}
\hline $\begin{array}{l}\text { Permeability } \\
\text { Porosity } \\
\text { Pore compressibility } \\
\text { Aquifer thickness }\end{array}$ & $\begin{array}{l}\mathrm{k}=10^{-13} \mathrm{~m}^{2} \\
\phi=0.12 \\
\mathrm{c}=4.5 \times 10^{-10} \mathrm{~Pa}^{-1} \\
100 \mathrm{~m}\end{array}$ \\
\hline Relati & \\
\hline $\begin{array}{l}\text { liquid: van Genuchten function (1980) } \\
\qquad \mathrm{k}_{\mathrm{rl}}=\sqrt{\mathrm{S}^{*}}\left\{1-\left(1-\left[\mathrm{S}^{*}\right]^{1 / \lambda}\right)^{\lambda}\right\}^{2} \\
\text { irreducible water saturation } \\
\text { exponent }\end{array}$ & $\begin{array}{l}\mathrm{S}^{*}=\left(\mathrm{S}_{1}-\mathrm{S}_{\mathrm{lr}}\right) /\left(1-\mathrm{S}_{\mathrm{lr}}\right) \\
\mathrm{S}_{\mathrm{lr}}=0.30 \\
\lambda=0.457\end{array}$ \\
\hline $\begin{array}{l}\text { gas: Corey curve (1954) } \\
\qquad \mathrm{k}_{\mathrm{rg}}=(1-\hat{\mathrm{S}})^{2}\left(1-\hat{\mathrm{S}}^{2}\right) \\
\text { irreducible gas saturation }\end{array}$ & $\begin{array}{l}\hat{S}=\frac{\left(S_{1}-S_{1 r}\right)}{\left(1-S_{1 r}-S_{g r}\right)} \\
S_{g r}=0.05\end{array}$ \\
\hline Capillary pressure & \\
\hline $\begin{array}{l}\text { van Genuchten function }(1980) \\
\qquad \mathrm{P}_{\text {cap }}=-\mathrm{P}_{0}\left(\left[\mathrm{~S}^{*}\right]^{-1 / \lambda}-1\right) 1-\lambda \\
\text { irreducible water saturation } \\
\text { exponent } \\
\text { strength coefficient }\end{array}$ & $\begin{array}{l}\mathrm{S}^{*}=\left(\mathrm{S}_{1}-\mathrm{S}_{\mathrm{lr}}\right) /\left(1-\mathrm{S}_{\mathrm{lr}}\right) \\
\mathrm{S}_{\mathrm{lr}}=0.0 \\
\lambda=0.457 \\
\mathrm{P}_{0}=19.61 \mathrm{kPa}\end{array}$ \\
\hline
\end{tabular}

Table A.2 Initial conditions and injection specifications

\begin{tabular}{|l|l|}
\hline Pressure & $120 \mathrm{bar}$ \\
\hline Temperature & $45^{\circ} \mathrm{C}$ \\
\hline Salinity & $15 \mathrm{wt} .-\% \mathrm{NaCl}$ \\
\hline $\mathrm{CO} 2$ injection rate & $100 \mathrm{~kg} / \mathrm{s}$ \\
\hline
\end{tabular}




\section{APPENDiX B. Test Problem 4: CO2 Discharge Along a Fault Zone*}

\section{INTRODUCTION AND GENERAL DESCRIPTION}

This problem explores $\mathrm{CO} 2$ loss from storage through a leaky fault, using a highly simplified 1-D linear flow geometry. It is envisioned that an aquifer into which $\mathrm{CO} 2$ disposal is made is intersected by a vertical fault, which establishes a connection through an otherwise impermeable caprock to another aquifer $500 \mathrm{~m}$ above the storage aquifer (Fig. B.1a). This situation is idealized by assuming 1-D flow geometry and constant pressure boundary conditions as shown in Fig. B.1b (Pruess and García, 2000).

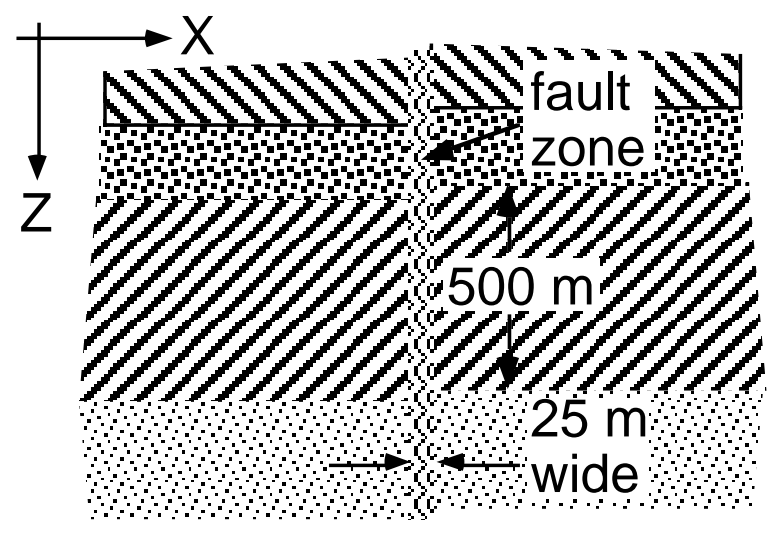

(a)

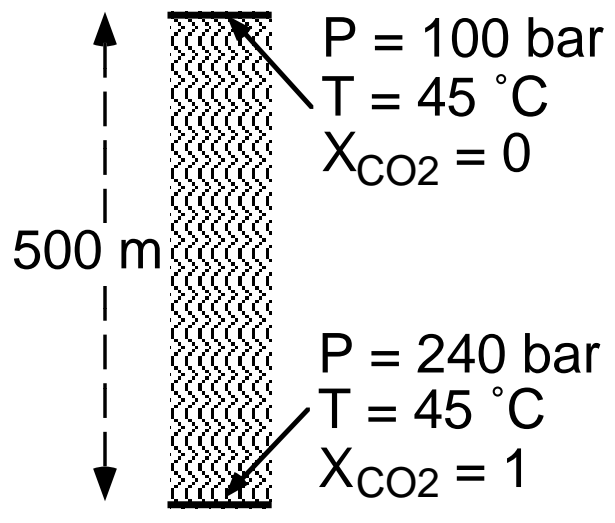

(b)

Figure B.1 Schematic of the fault zone model (a) and applied boundary conditions (b).

\section{LIST OF PROCESSES BEING STUDIED}

Immiscible displacement of water by $\mathrm{CO} 2$ subject to pressure, gravity, and capillary pressure effects.

Change of fluid density, viscosity, and $\mathrm{CO} 2$ solubility with pressure.

Formation dry-out.

\section{DEFINITION OF THE PROBLEM AND INPUT DATA}

Hydrogeologic parameters are identical to those of problem 3 (Table A.1), except that porosity is increased to $35 \%$. The fault zone is assumed to be $25 \mathrm{~m}$ wide and $500 \mathrm{~m}$ tall, with boundary conditions as given in Fig. D.1b. The reservoir fluid is assumed to be pure water (no salinity). Initial conditions are pressures in hydrostatic equilibrium relative to $\mathrm{P}=100 \mathrm{bar}$ at the top; temperature is held constant at $\mathrm{T}=45^{\circ} \mathrm{C}$ throughout.

\footnotetext{
* proposed by Karsten Pruess; e-mail: K_Pruess@lbl.gov
} 


\section{PROBLEM VARIATIONS}

Include salinity of the aqueous phase and permeability changes due to precipitation. Include nonisothermal effects. Assume gas composition is $50 \% \mathrm{CO} 2,50 \% \mathrm{~N} 2$.

\section{DEFINITION OF RESULTS TO BE CALCULATED}

Data on $\mathrm{CO} 2$ and water density and viscosity, and $\mathrm{CO} 2$ solubility, for the range of thermodynamic conditions encountered in the problem. Vertical profiles of gas saturation, fluid pressure, and dissolved $\mathrm{CO} 2$ mass fraction at different times. $\mathrm{CO} 2$ inventory in gas and liquid phases after $10^{7}$ seconds. Mass flow rates of $\mathrm{CO} 2$ at the bottom and of water at the top vs. time (normalized for a 1 $\mathrm{m}$ thick section).

\section{COMPARISON CRITERIA}

Results should match to with $+/-5 \%$.

\section{REFERENCES}

Pruess, K. and J. García. Multiphase Flow Dynamics During CO2 Injection into Saline Aquifers, submitted to Environmental Geology, September 2000. 


\section{APPENDix C. Test Problem 7: $\mathrm{CO}_{2}$ Injection into a 2-D Layered Brine Formation\#}

\section{INTRODUCTION AND GENERAL DESCRIPTION}

This test problem is patterned after the $\mathrm{CO}_{2}$ injection project at the Sleipner Vest field in the Norwegian sector of the North Sea, and is intended to investigate the dominant physical processes associated with the injection of supercritical $\mathrm{CO}_{2}$ into a layered medium. Significant simplifications have been made, the most important of which is the assumption of isothermal conditions $\left(37^{\circ} \mathrm{C}\right.$, the ambient temperature of the formation). $\mathrm{CO}_{2}$ injection rates (1,000,000 tonnes per year), system geometry, and system permeabilities correspond approximately to those at Sleipner, although no attempt was made to represent details of the permeability structure within the host formation. Injection of the supercritical $\mathrm{CO}_{2}$, which is less dense than the saline formation waters into which it is injected, causes it to rise through the formation. Its rate of ascent, however, is limited by the presence of four relatively low permeability shales. The top and bottom of the formation is assumed to be impermeable. The only reactive chemistry considered in this problem is the dissolution of $\mathrm{CO}_{2}$ in the aqueous phase.

\section{LIST OF PROCESSES BEING STUDIED}

a) Gravity-driven advection in response to strong vertical and lateral density gradients induced by the injection of $\mathrm{CO}_{2}$ into saline formation water.

b) Density, viscosity, and solubility formulations of water and $\mathrm{CO}_{2}$ as a function of pressure and temperature $(\mathrm{P}$ and $\mathrm{T})$.

\section{DEFINITION OF THE PROBLEM AND INPUT DATA}

System Geometry:

The system is idealized as a two dimensional symmetric domain perpendicular to the horizontal injection well which has a screen length of 100 meters (Figure C.1). A one meter thick section perpendicular to the horizontal well is considered. The thickness of the formation at the injection site is 184 meters. The injection point is 940 meters below the sea floor, while the ocean depth at the site is 80 meters. The formation is assumed to consist of four lower permeability shale units 3 meters thick which are distributed within the high permeability sand. Each shale unit is separated by 30 meters. The well is 30 meters below the lowest shale unit, while the bottom of the aquifer is another 22 meters below the well.

\# proposed by Carl Steefel; e-mail: steefel1@1lnl.gov 


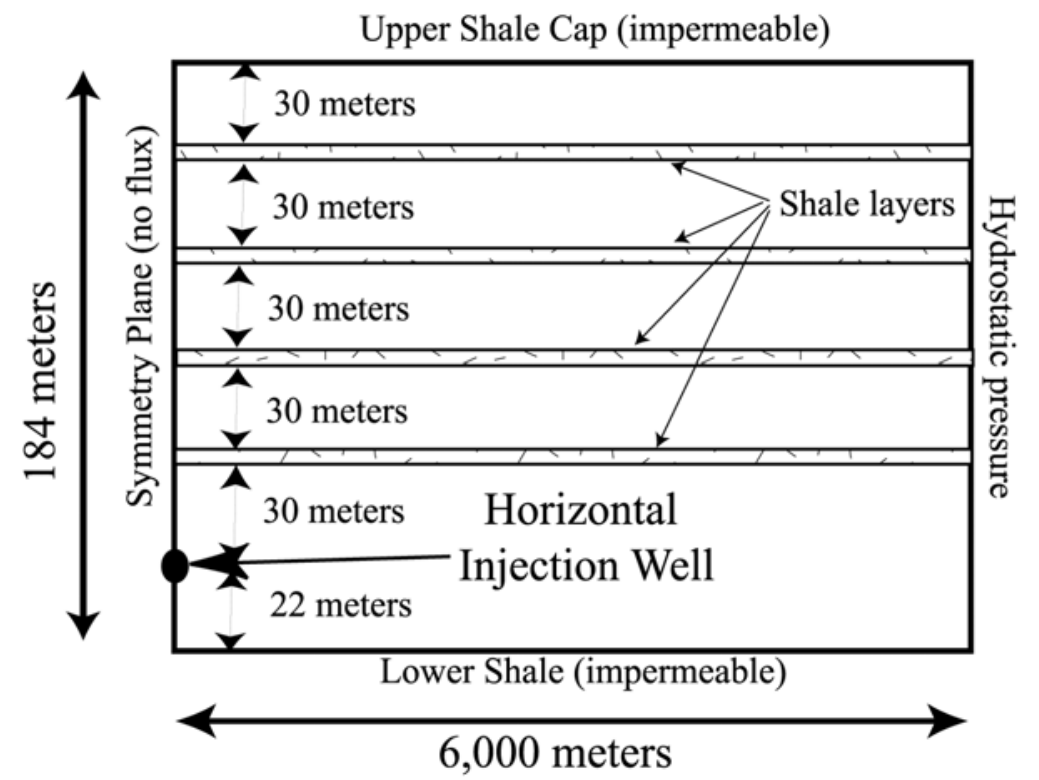

Figure C.1 Schematic representation of geometry for $\mathrm{CO} 2$ injection in Utsira Formation.

\section{Boundary conditions:}

No heat or mass flux is allowed across any of the boundaries except the vertical boundary 6,000 meters from the injection well. This boundary is fixed at hydrostatic pressure, thus allowing flow into and out of the domain so as to avoid overpressuring the formation. The 6,000 meter boundary is chosen, however, to be far enough from the injection well that the $\mathrm{CO}_{2}$ does not reach this boundary after 2 years of injection.

\section{Initial conditions (Table C.1):}

a) $\mathrm{T}=37{ }^{\circ} \mathrm{C}$ (isothermal throughout)

b) $\mathrm{P}=$ hydrostatic (approximately 110 bars at injection point, approximately 90 bars at top of formation).

c) $\mathrm{CO}_{2}$ in the aqueous phase in equilibrium with a $\mathrm{P}_{\mathrm{CO} 2}$ of 0.5 bars, a typical value for sedimentary formation waters at the temperature we are considering.

Table C.1 Initial conditions and injection specifications

\begin{tabular}{|l|l|}
\hline Pressure at well & $110 \mathrm{bar}$ \\
\hline Temperature & $37^{\circ} \mathrm{C}$ \\
\hline Salinity & $3.2 \mathrm{wt} .-\% \mathrm{NaCl}$ \\
\hline $\mathrm{CO} 2$ injection rate & $0.1585 \mathrm{~kg} / \mathrm{s}$ in half space \\
\hline
\end{tabular}


Injection specifications (Table C.1):

a) Temperature $=37^{\circ} \mathrm{C}$

b) Injection rate: $31.7 \mathrm{~kg} / \mathrm{s}$ over entire screen length (100 meters), corresponding to $0.317 \mathrm{~kg} / \mathrm{s}$ for the 1 meter thick section considered. Because of symmetry, injection rate in half space is therefore $0.1585 \mathrm{~kg} / \mathrm{s}$.

c) Height of well cell: 1 meter.

d) Injection time scale: 2 years

Input data (Table C.2):

a) Capillary pressure and relative permeability described with van Genuchten parameters (both liquid and gas mobile). Porosity is $35 \%$ for sands, $10.25 \%$ for shales.

b) Fully saturated permeability ( $\mathrm{k}=3 \times 10^{-12} \mathrm{~m}^{2}$ in sand layers, $10^{-14} \mathrm{~m}^{2}$ in shales)

c) Density, viscosity, and solubility in water of $\mathrm{CO}_{2}$ as functions of $\mathrm{P}$ and $\mathrm{T}$ (Span and Wagner, 1996).

d) Vapor-liquid equilibrium properties of water.

\section{PROBLEM VARIATIONS}

Include non-isothermal effects by making the $\mathrm{CO}_{2}$ injection temperature equal to $65{ }^{\circ} \mathrm{C}$.

\section{RESULTS TO BE CALCULATED}

Liquid and gas saturations as a function of space and time. $\mathrm{CO}_{2}$ concentration in the aqueous phase as a function of space. Gas and liquid fluxes.

\section{COMPARISON CRITERIA}

Results should match within $+/-5 \%$. 
Table C.2 Hydrogeologic parameters

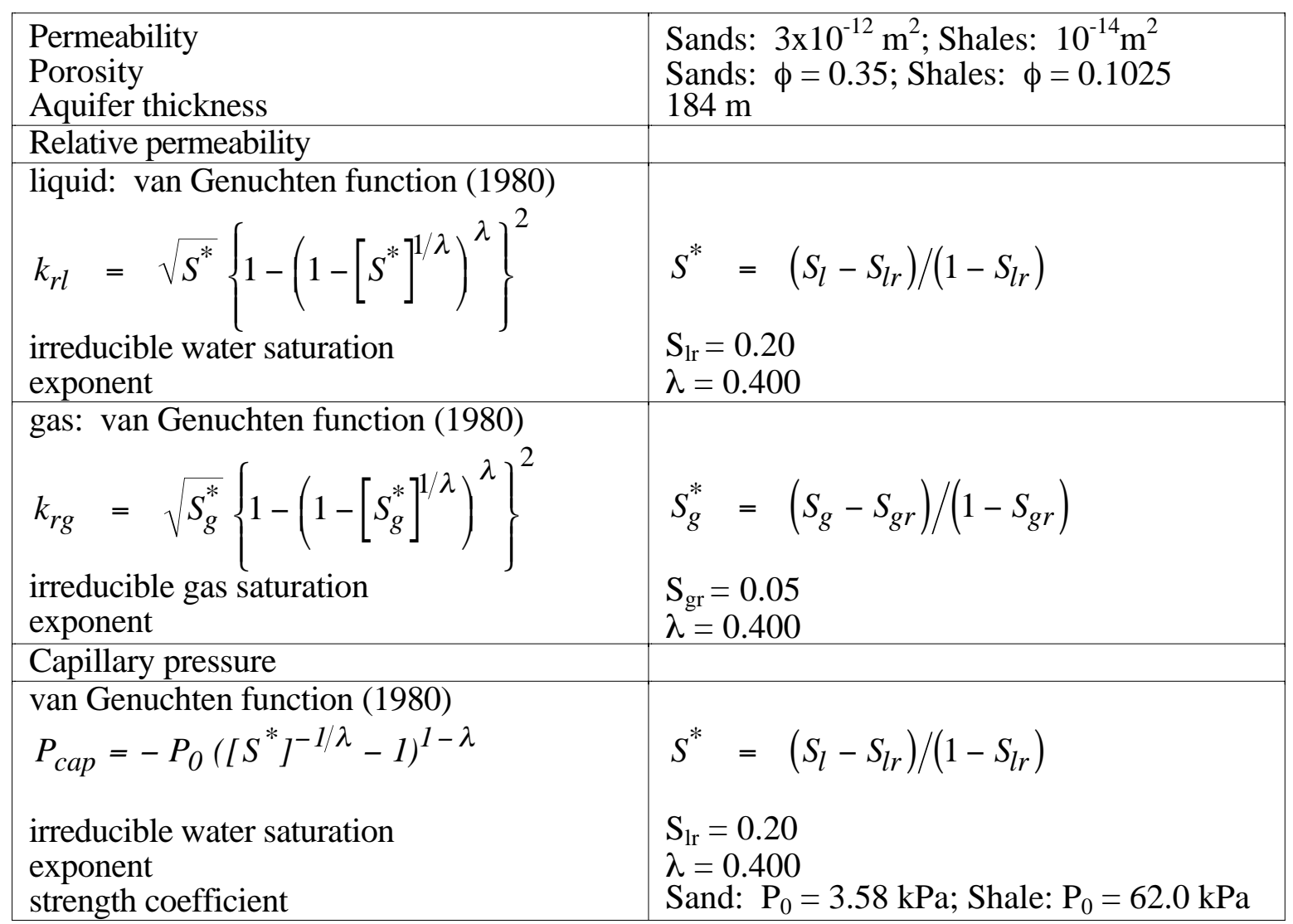

\section{REFERENCES}

van Genuchten, M.Th. A Closed-Form Equation for Predicting the Hydraulic Conductivity of Unsaturated Soils, Soil Sci. Soc. Am. J., Vol. 44, pp. 892 - 898, 1980.

Span, R. and W. Wagner. A New Equation of State for Carbon Dioxide Covering the Fluid Region from the Triple-Point Temperature to $100 \mathrm{~K}$ at Pressures up to $800 \mathrm{MPa}$, J. Phys. Chem. Ref. Data, Vol. 25, No. 6, pp. 1509 - 1596, 1996. 